PNNL-24378

\title{
Investigations into Alternative Desorption Agents for Amidoxime- Based Polymeric Uranium Adsorbents
}

\section{Final Report}

\section{DOE-NE Milestone Report: M2FT-15PN0310051}

Gary A Gill, Li-Jung Kuo, Jonathan Strivens, and Jordana Wood

Pacific Northwest National Laboratory, Marine Sciences Laboratory, Sequim, WA 98382

Chien Wai

LCW Supercritical Technologies, Inc., Seattle, WA

Horng-Bin Pan

University of Idaho, Moscow, ID

June 2015

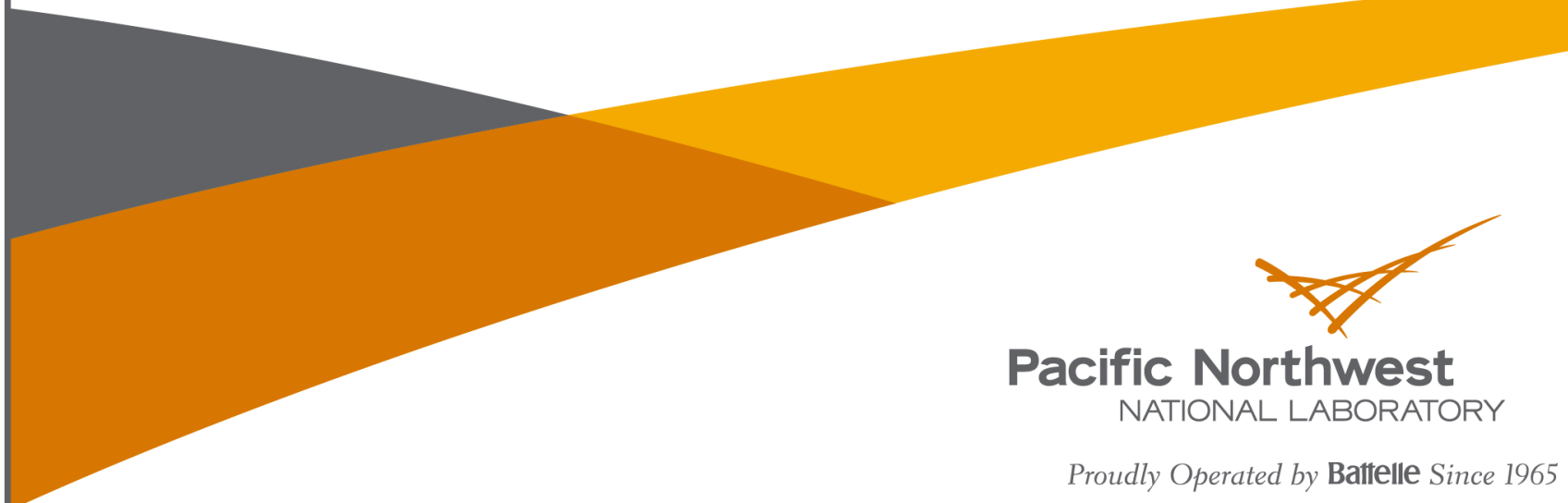




\title{
DISCLAIMER
}

This report was prepared as an account of work sponsored by an agency of the United States Government. Neither the United States Government nor any agency thereof, nor Battelle Memorial Institute, nor any of their employees, makes any warranty, express or implied, or assumes any legal liability or responsibility for the accuracy, completeness, or usefulness of any information, apparatus, product, or process disclosed, or represents that its use would not infringe privately owned rights. Reference herein to any specific commercial product, process, or service by trade name, trademark, manufacturer, or otherwise does not necessarily constitute or imply its endorsement, recommendation, or favoring by the United States Government or any agency thereof, or Battelle Memorial Institute. The views and opinions of authors expressed herein do not necessarily state or reflect those of the United States Government or any agency thereof.

\author{
PACIFIC NORTHWEST NATIONAL LABORATORY \\ operated by \\ BATTELLE \\ for the \\ UNITED STATES DEPARTMENT OF ENERGY \\ under Contract DE-AC05-76RL01830 \\ Printed in the United States of America \\ Available to DOE and DOE contractors from the \\ Office of Scientific and Technical Information, \\ P.O. Box 62, Oak Ridge, TN 37831-0062; \\ ph: (865) 576-8401 \\ fax: $(865) 576-5728$ \\ email: reports@adonis.osti.gov \\ Available to the public from the National Technical Information Service \\ 5301 Shawnee Rd., Alexandria, VA 22312 \\ ph: (800) 553-NTIS (6847) \\ email: $\underline{\operatorname{orders}(\boldsymbol{a} \text { ntis.gov }}<\mathrm{http}: / /$ www.ntis.gov/about/form.aspx $>$ \\ Online ordering: http://www.ntis.gov
}




\section{Investigations into Alternative Desorption Agents for Amidoxime-Based Polymeric Uranium Adsorbents}

\section{Final Report}

Prepared for: U. S. Department of Energy, Office of Nuclear Energy, Fuel Cycle Research and Development Program, Fuel Resources Program

Prepared by: Gary A Gill, Li-Jung Kuo, Jonathan Strivens, and Jordana Wood Pacific Northwest National Laboratory

Marine Sciences Laboratory, Sequim, WA 98382

Chien Wai

LCW Supercritical Technologies, Inc.

Seattle, WA

Horng-Bin Pan

University of Idaho

Moscow, ID

Milestone Number: M2FT-15PN0310051

Milestone Due Date: 6-15-2015

U. S. DOE-NE Program Manager: Dr. Stephen Kung

FCRD Document Number:

Milestone Level: M2

PNNL Erica Clearance Number: PNNL-24378

Prepared for: the U.S. Department of Energy under Contract DE-AC05-76RL01830, Pacific

Northwest National Laboratory, Richland, Washington 99352 


\section{Executive Summary}

Amidoxime-based polymeric braid adsorbents that can extract uranium (U) from seawater are being developed to provide a sustainable supply of fuel for nuclear reactors. A critical step in the development of the technology is to develop elution procedures to selectively remove $\mathrm{U}$ from the adsorbents and to do so in a manner that allows the adsorbent material to be reused. This study investigates use of high concentrations of bicarbonate along with targeted chelating agents as an alternative means to the mild acid elution procedures currently in use for selectively eluting uranium from amidoxime-based polymeric adsorbents.

Three different adsorbent recycling approaches were tested: (1) $0.5 \mathrm{M} \mathrm{HCl}$ elution, (2) $3 \mathrm{M} \mathrm{KHCO}_{3}$ elution and (3) $3 \mathrm{M} \mathrm{KHCO}_{3}$ elution, followed by elution with Tiron to remove Fe. Amidoxime-based polymeric braid adsorbents were deployed in a flume system exposed to ambient filtered seawater at $20 \pm$ $1.5^{\circ} \mathrm{C}$ for a multi-cycle adsorbent reuse study. Adsorption kinetics and adsorption capacity were assessed using time series determinations of uranium adsorption and one-site ligand saturation modeling. Adsorbents were further characterized by spectroscopic and microscopic techniques to investigate potential chemical and physical alterations of adsorbent materials after seawater exposure and adsorbent recycling.

All three elution schemes removed $88 \%$ to $90 \%$ of the uranium sequestered by the adsorbent after 42 days of exposure in natural seawater. The adsorbent's ability to recover U following an elution cycle varied substantially with the treatment applied. There was a substantial reduction $(>80 \%)$ in the $\mathrm{U}$ adsorption capacity in subsequent adsorbent reuse following $0.5 \mathrm{M} \mathrm{HCl}$ acid elution and $\mathrm{KOH}$ reconditioning. The specific reason for this large reduction in capacity is currently unknown, but it suggests that the combination of acid elution and $\mathrm{KOH}$ reconditioning causes physical and/or chemical damage to the adsorbent. Adsorbent reuse following $3 \mathrm{M} \mathrm{KHCO}_{3}$ elution (without subsequent reconditioning) results in a higher $\mathrm{U}$ adsorption capacity (33\% to $54 \%$ of the original capacity) compared to acid elution and reconditioning, but below desired recovery levels. Including Tiron elution after $\mathrm{KHCO}_{3}$ elution does not appear to significantly improve $\mathrm{U}$ recovery during adsorbent reuse, despite the fact that Tiron can remove a significant amount $(\sim 90 \%)$ of the adsorbed Fe. This implies that removing other metal ions that compete with $\mathrm{U}$ for binding sites on the adsorbent may not benefit the adsorbent's overall performance and reuse.

Fourier transform infrared spectroscopy (FTIR) measurements showed that approximately a 20\% conversion of amidoxime groups to carboxylate groups occured to all three AF1L2R3 braided adsorbents used in the elution study during 42 days of seawater exposure. About a $20 \%$ decrease in amidoxime groups was observed after $\mathrm{HCl}$ elution and $\mathrm{KOH}$ reconditioning. Physical damage to the adsorbent structure after $\mathrm{HCl}$ elution and $\mathrm{KOH}$ reconditioning were also observed from scanning electron microscope (SEM) images. FTIR investigations revealed no chemical changes in the absorbent occurring after either the $\mathrm{KHCO}_{3}$ elution or the $\mathrm{KHCO}_{3}+$ Tiron elution. SEM images did not reveal any structural damage to adsorbents treated with $\mathrm{KHCO}_{3}$ elution or the $\mathrm{KHCO}_{3}+$ Tiron elution. These observations suggest that $\mathrm{KHCO}_{3}$ and Tiron elutions have minimal impact on the physical and chemical integrity of amidoxime-based polymeric adsorbents compared to that observed with the $0.5 \mathrm{M} \mathrm{HCl}$ elution followed by $\mathrm{KOH}$ reconditioning for adsorbent reuse. 
All three recycling approaches tested with the Oak Ridge National Laboratory (ORNL) AF1L2R3 amidoxime-based polymeric adsorbent produced $\mathrm{U}$ adsorption capacities upon reuse below expectation. The reason for the reduction in capacity upon reuse is currently unknown. The $\mathrm{KHCO}_{3}$ elution process was shown to be very selective for removing $U$ from amidoxime-based adsorbents, a very significant feature that can be capitalized on for the overall $U$ recovery process. If the mechanisms responsible for the loss of adsorption capacity upon elution can be identified, it is highly likely that an elution process can be developed that results in a much improved adsorption capacity upon reuse. As this report is being submitted, efforts are underway at ORNL and Pacific Northwest National Laboratory to investigate the role of the degree of grafting and amidoximation conditions on adsorbent capacity. Optimizing these parameters may significantly improve adsorbent durability and reuse. 


\section{Acronyms and Abbreviations}

DOM

FTIR

JAEA

MSL

NIST

ORNL

PNNL

RIGP

SEM dissolved organic matter

Fourier transform infrared spectroscopy

Japan Atomic Energy Agency

Marine Sciences Laboratory

National Institute of Standards and Technology

Oak Ridge National Laboratory

Pacific Northwest National Laboratory

radiation-induced graft polymerization

scanning electron microscope 



\section{Contents}

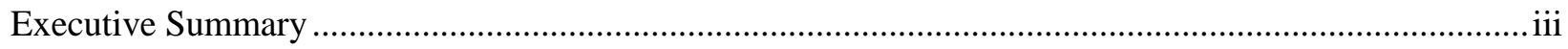

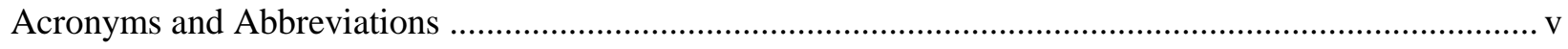

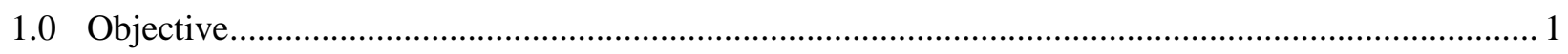

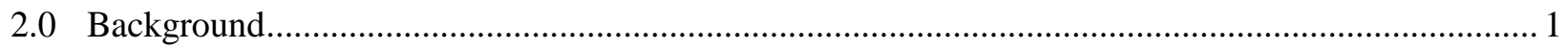

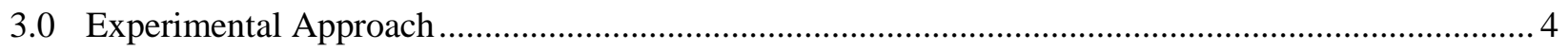

3.1 PNNL Ambient Seawater Exposure System ............................................................... 4

3.1.1 Exposure of Braided Adsorbent Material.................................................................... 5

3.1.2 One-Site Ligand Saturation Modeling ........................................................................ 8

3.2 Recycling Approaches for Reuse of Amidoxime-Based Uranium Adsorbents ......................... 8

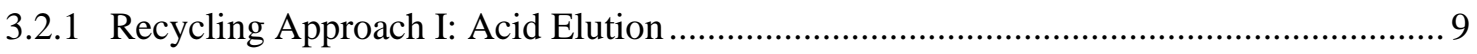

3.2.2 Recycling Approach II: Bicarbonate Elution ........................................................... 10

3.2.3 Recycling Approach III: Bicarbonate Elution Followed by Tiron Elution ..................... 11

3.3 Preparation of Amidoxime-based Polymeric Adsorbent Braids ............................................. 12

3.4 Multi-cycle Adsorbent Reuse Test .................................................................................. 12

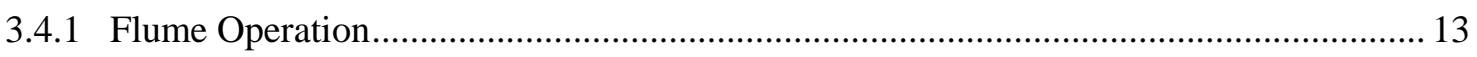

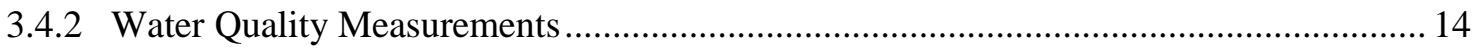

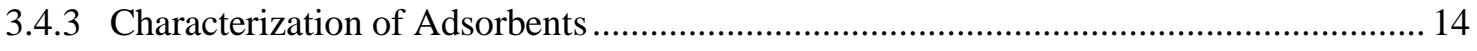

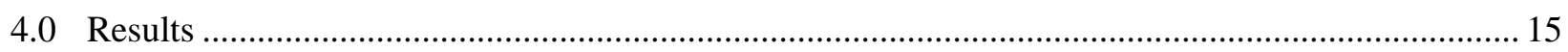

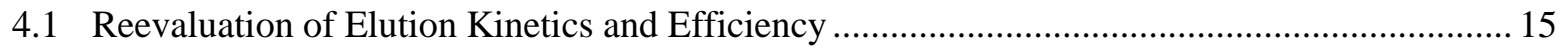

4.2 Adsorbent Recycle Experiment - Initial Seawater Exposure ................................................ 17

4.3 Adsorbent Recycling Experiment - Acid Elution + KOH Reconditioning.............................. 17

4.4 Adsorbent Recycling Experiment $-\mathrm{KHCO}_{3}$ Elution .......................................................... 18

4.5 Adsorbent Recycling Experiment $-\mathrm{KHCO}_{3}$ Elution + Tiron Elution .................................... 19

4.6 Adsorbent Recycling Experiment - Trace Element Removal After Recycling Elution ............ 20

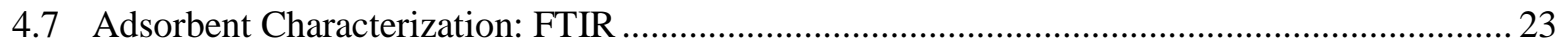

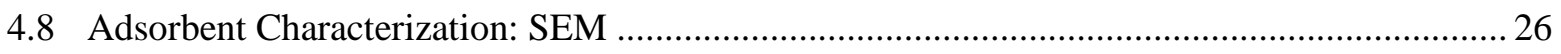

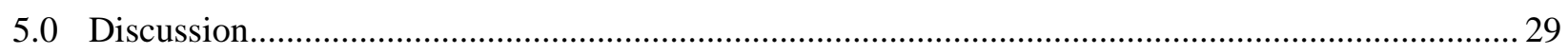

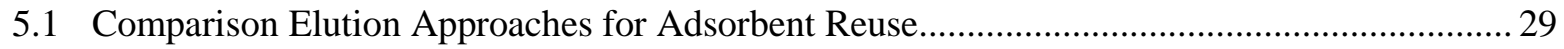

5.2 Effects of Seawater Exposure and Elution Recycling Approaches on the Physical and Chemical Properties of Amidoxime-Based Polymeric Adsorbents .......................................... 31

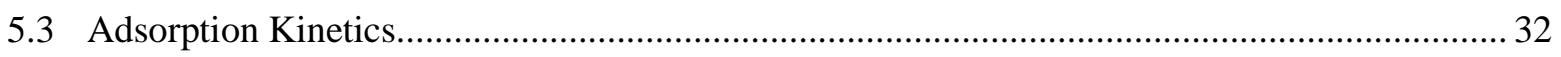

5.4 Effect of DOM Removal from Seawater-Exposed Adsorbents on U Adsorption

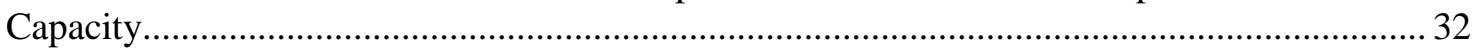

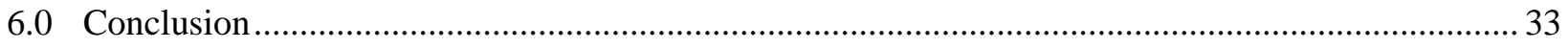

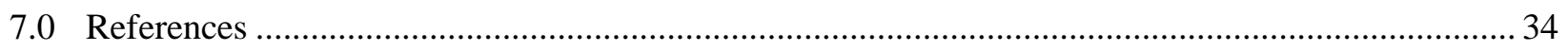




\section{Figures}

Figure 1. Potential amidoxime-based moieties that can be produced from production of adsorbent using radiation induced grafting. $\mathrm{H}_{2} \mathrm{~A}=$ glutarimidedioxime, $\mathrm{H}_{2} \mathrm{~B}$ = glutardiamidoxime, $\mathrm{HC}$ = glutarimidoxioxime.

Figure 2. Distribution of uranyl species in water with uranium $(0.252 \mathrm{M})$, single molecule glutarimidedioxime $\left(\mathrm{H}_{2} \mathrm{~A}, 0.504 \mathrm{M}\right)$, and bicarbonate (a) $1 \times 10^{-3} \mathrm{M}$, (b) $1 \mathrm{M}$, and (c) $3 \mathrm{M}$............... 3

Figure 3. Solubility of $\mathrm{NaHCO}_{3}$ and $\mathrm{KHCO}_{3}$ in water at different temperatures. ................................... 4

Figure 4. Layout and components of seawater manifold system for exposing uranium adsorbents to ambient seawater.

Figure 5. 12-port seawater manifold and PNNL-style flow-through columns containing uraniumadsorbent material

Figure 6. Conceptual side view of flume showing fresh seawater inlet and recirculation system.............. 6

Figure 7. Eight-foot flume with adsorbent material in place for marine testing. Water recirculation is turned off for the picture.

Figure 8. Adsorbent braid attached to a short length of 1/4-inch polyethylene tubing. The tubing is then inserted into a block attached to the bottom of the flume (see Figure 7).

Figure 9. Four-foot flume. The recirculation pump is on the right-hand side. Recirculated water passes through the flow meter (yellow section of piping) and water flow is controlled by the (red) valve at outlet of the pump. Fresh seawater inflow is delivered from the manifold (behind the flume) through poly tubing inserted through the top of the flume lid.

Figure 10. Kinetics of uranium removal from ORNL adsorbent 38H6 using $1 \mathrm{M} \mathrm{HCl}$ at room temperature.

Figure 11. Kinetics of uranium and transition metals removal from ORNL adsorbent 38H6 using $1 \mathrm{M} \mathrm{HCl}$ at room temperature.

Figure 12. Rates of uranium elution from the sorbent at different temperatures and bicarbonate concentrations.

Figure 13. FTIR spectra of the ORNL-AF1 amidoxime-based polymeric adsorbent before and after Tiron elution.

Figure 14. Experimental design of the steps involved in a multi-cycle adsorbent reuse test

Figure 15. Uranium leaching kinetics from different adsorbents using $0.5 \mathrm{M} \mathrm{HCl}$ solution at room temperature.

Figure 16. Uranium leaching kinetics from different adsorbents using $3 \mathrm{M} \mathrm{KHCO}_{3}$ solution at $40^{\circ} \mathrm{C}$.

Figure 17. Iron leaching kinetics from different adsorbents using $0.5 \mathrm{M}$ Tiron solution at $40^{\circ} \mathrm{C}$.

Figure 18. Time-dependent measurements of uranium adsorption capacity of three identical ORNL AF1L2R3 adsorbent braids. Best fit lines drawn through the data points were generated using a one-site ligand saturation model. Note that the 21-day and 42-day time point samples of three braids are all in duplicate.

Figure 19. Time-dependent measurements of uranium adsorption capacity with ORNL AF1L2R3 braid recycled using $0.5 \mathrm{M} \mathrm{HCl}$ leaching followed by $\mathrm{KOH}$ reconditioning. Data include the initial seawater exposure and the first and second seawater reexposures after uranium was removed. Lines drawn through the data points were generated with a one-site ligand saturation model. The measured adsorption capacity at each time point for the seawater reexposure (first and second recycles) was background corrected by subtracting the residual 
uranium concentration after $0.5 \mathrm{M} \mathrm{HCl}$ leaching (Table 5). The 21-day and 42-day data points were done in duplicate. All data were normalized to a salinity of $35 \mathrm{psu}$.

Figure 20. Time-dependent measurements of uranium adsorption capacity with ORNL AF1L2R3 braid recycled by $3 \mathrm{M} \mathrm{KHCO}_{3}$ leaching. Data include the initial seawater exposure and the first and second seawater reexposures after uranium was removed. Lines drawn through the data points were generated with a one-site ligand saturation model. The measured adsorption capacity at each time point from seawater reexposure (first and second recycles) was background corrected by subtracting the residual uranium concentration after $3 \mathrm{M}$ $\mathrm{KHCO}_{3}$ leaching (from Table 6). The 21-day and 42-day data points were done in duplicate. All data were normalized to a salinity of $35 \mathrm{psu}$.....

Figure 21. Time-dependent measurements of uranium adsorption capacity with ORNL AF1L2R3 braid recycled by $3 \mathrm{M} \mathrm{KHCO}_{3}$ leaching followed by $0.5 \mathrm{M}$ Tiron elution. Data include the initial seawater exposure and the first and second seawater reexposures after uranium was removed. Lines drawn through the data points were generated with the one-site ligand saturation model. The measured adsorption capacity at each time point from seawater reexposure (first and second cycles) was background corrected by subtracting the residual uranium concentration after $3 \mathrm{M} \mathrm{KHCO}_{3}$ leaching + 0.5 M Tiron elution (from Table 7). Note that the 21-day and 42-day data points were duplicates. All data were normalized to a salinity of 35 psu.

Figure 22. Comparison of trace elements of ORNL AF1L2R3 braid leached by $0.5 \mathrm{M} \mathrm{HCl}+$ $2.5 \% \mathrm{KOH}$ reconditioning for reuse (two reuse cycles): (a) percentage removal of trace element by $0.5 \mathrm{M} \mathrm{HCl}$ leaching; (b) distribution of trace elements adsorbed by braid after 42-day seawater exposure; and (c) percentage change of adsorbed trace element by reused braid relative to those by original braid (before reuse).

Figure 23. Comparison of trace elements of ORNL AF1L2R3 braid leached by $3 \mathrm{M} \mathrm{KHCO}_{3}$ leaching for reuse (two reuse cycles): (a) percentage removal of trace element by $0.5 \mathrm{M} \mathrm{HCl}$ leaching; (b) distribution of trace elements adsorbed by braid after 42-day seawater exposure; and (c) percentage change of adsorbed trace element by reused braid relative to those by original braid (before reuse).

Figure 24. Comparison of trace elements of ORNL AF1L2R3 braid leached by $3 \mathrm{M} \mathrm{KHCO}_{3}$ leaching + 0.5 M Tiron leaching for reuse (two reuse cycles): (a) percentage removal of trace element by $0.5 \mathrm{M} \mathrm{HCl}$ leaching; (b) distribution of trace elements adsorbed by braid after 42-day seawater exposure; and (c) percentage change of adsorbed trace element by reused braid relative to those by original braid (before reuse)

Figure 25. FTIR spectrum of the AF1L2R3 sorbent after conditioning with $2.5 \% \mathrm{KOH}$ solution at $80^{\circ} \mathrm{C}$ for 1 hour.

Figure 26. FTIR spectra of the AF1L2R3 braid sorbents by three different elution methods: (a) $\mathrm{KHCO}_{3}$ elution, (b) $\mathrm{KHCO}_{3}+$ Tiron elution, and (c) $\mathrm{HCl}$ elution $+\mathrm{KOH}$ reconditioning in the region 800 to $2000 \mathrm{~cm}^{-1}$. The spectra are normalized to the $-\mathrm{CH}_{2}-$ asymmetrical stretching peak at $2918 \mathrm{~cm}^{-1}$.

Figure 27. SEM image of the amidoxime grafted high-surface-area polyethylene AF1L2R3 fiber obtained from ORNL prior to KOH conditioning.

Figure 28. SEM image of the high-surface-area polyethylene AF1L2R3 fibers after 1 hour of $\mathrm{KOH}$ conditioning at $80^{\circ} \mathrm{C}$. 27

Figure 29. SEM image of the KOH treated AF1L2R3 sorbent after 42 days seawater exposure.............. 28

Figure 30. SEM image of the AF1L2R3 sorbent after $\mathrm{HCl}$ elution and $\mathrm{KOH}$ reconditioning. .29

Figure 31. Comparison of $\mathrm{U}$ adsorption capacity for ORNL AF1 adsorbent fibers treated with $\mathrm{NaOH}$ after the first reuse (red bar) with results obtained from the $3 \mathrm{M} \mathrm{KHCO}_{3}$ elution/recycling experiment (blue columns). The percentage numbers above the columns 
are percentage recovery of $U$ adsorption capacity relative to the adsorption capacity of the first reused adsorbent.

\section{Tables}

Table 1. PNNL flume dimensions

Table 2. Elution of $\mathrm{Fe}$ and $\mathrm{V}$ from amidoxime-based polymeric sorbents by different metal chelating ligands. ${ }^{\text {(a) }}$

Table 3. Finalized elution conditions for the three elution methods.

Table 4. One-site ligand saturation modeling of time-dependent measurements of three identical braids used in recycling study. All data were normalized to a salinity of $35 \mathrm{psu}$.

Table 5. One-site ligand saturation modeling of time-dependent measurements of the AF1L2R3 braid recycled by using $0.5 \mathrm{M} \mathrm{HCl}$ leaching followed by $\mathrm{KOH}$ reconditioning. All data were normalized to a salinity of $35 \mathrm{psu}$.

Table 6. One-site ligand saturation modeling of time-dependent measurements of the AF1L2R3 braid recycled using $3 \mathrm{M} \mathrm{KHCO}_{3}$ leaching. All data were normalized to a salinity of $35 \mathrm{psu}$

Table 7. One-site ligand saturation modeling of time-dependent measurements of the AF1L2R3 braid recycled by using $3 \mathrm{M} \mathrm{KHCO}_{3}$ leaching followed by $0.5 \mathrm{M}$ Tiron elution. All data were normalized to a salinity of 35 psu.

Table 8. Peak intensity of $\mathrm{N}-\mathrm{O}$ stretching $\left(928 \mathrm{~cm}^{-1}\right)$ and ratio of $\mathrm{C}=\mathrm{N} /-\mathrm{COO}^{-}$stretching $\left(\mathrm{I}_{1643} / \mathrm{I}_{1559}\right)$ of the AF1L2R3 braid sorbents under three different elution methods. The peak intensities are normalized to $-\mathrm{CH}_{2}-$ asymmetrical stretching peak at $2918 \mathrm{~cm}^{-1}$.

Table 9. Percentage removal of U, Fe, and V from AF1L2R3 braids after being leached by three different methods. The percentage changes were calculated relative to the adsorption data of adsorbent before being reused.

Table 10. Percentage recovery in uranium adsorption capacity of the ORNL AF1L2R3 braided adsorbent after being recycled by three different elution methods. Shown are the relative change in adsorption capacity following an elution scheme and a subsequent 42-day seawater exposure and the modeled saturation capacity. The percentage change was determined relative to the adsorption capacity obtained on the initial seawater exposure. 


\subsection{Objective}

Pacific Northwest National Laboratory (PNNL) has a level 2 milestone (M2FT-15PN0310051) to demonstrate the alternative desorption agents that can effectively remove uranium from adsorbent materials under natural seawater conditions. This report describes the removal of uranium and other elements from amidoxime-based adsorbents using weak acid and concentrated bicarbonate solutions. Specific attention is given to adsorbent performance in multiple loading/stripping cycles.

\subsection{Background}

The Fuel Resources Program at the U.S. Department of Energy's Office of Nuclear Energy is developing adsorbent technology to extract uranium from seawater. This technology is being developed to provide a sustainable and economically viable supply of uranium fuel for nuclear reactors (DOE, 2010). A key component in the development of this technology is the ability to reuse the adsorbent material through many loading/elution cycles. Since adsorbent manufacturing represents a majority of the cost of extracting uranium from seawater, the more reuses of an individual adsorbent, the lower the cost of extracting uranium from seawater (Schneider and Sachde, 2013). Hence, understanding and optimizing procedures for the reuse of the absorbent material is a critical component of the technological development.

A common method for stripping uranium and other elements off the adsorbent material is the use of weak mineral acids (Omichi et al., 1986; Hirotsu et al., 1987; Egawa et al., 1990; Suzuki et al., 2000; Das et al., 2008; Seko et al., 2005). An alternative approach, which has seen some use in the literature, is to treat the adsorbent with a carbonate or bicarbonate solution (Egawa et al., 1993). The rationale behind this choice requires an understanding of the speciation of uranium under seawater conditions and the binding of uranium in seawater to amidoxime-based adsorbents.

Uranium exists in aqueous solution as the uranyl ion $\left(\mathrm{UO}_{2}{ }^{+}\right)$complexed with solution ligands. In seawater, the dominant forms of uranium are the tris-carbonato species, $\mathrm{UO}_{2}\left(\mathrm{CO}_{3}\right)_{3}^{-4}$, and its complexes with the major doubly charged cations in seawater, $\mathrm{Ca}^{2+}$ and $\mathrm{Mg}^{2+}$, to form the species $\mathrm{Ca}_{2}\left[\mathrm{UO}_{2}\left(\mathrm{CO}_{3}\right)_{3}\right]^{0}$, $\mathrm{Ca}\left[\mathrm{UO}_{2}\left(\mathrm{CO}_{3}\right)_{3}\right]^{2-}$, and $\mathrm{Mg}\left[\mathrm{UO}_{2}\left(\mathrm{CO}_{3}\right)_{3}\right]^{2-}$ (Leggett and Rao, 2015a).

Amidoxime-based polymeric adsorbents are among the most widely described and frequently used materials to extract uranium from seawater. A common method to produce these materials is through radiation-induced grafting, which can result in several possible binding sites on the polymeric adsorbent, including the monodendate, bidendate, and cyclic structures depicted in Figure 1. 
<smiles>O/N=C1/CCC/C(=N\O)N1</smiles>

$\mathrm{H}_{2} \mathrm{~A}$<smiles>N/C(CCC/C(N)=N/O)=N\O</smiles>

$\mathrm{H}_{2} \mathrm{~B}$<smiles>O=C1CCC/C(=N/O)N1</smiles>

$\mathrm{HC}$

Figure 1. Potential amidoxime-based moieties that can be produced from production of adsorbent using radiation induced grafting. $\mathrm{H}_{2} \mathrm{~A}=$ glutarimidedioxime, $\mathrm{H}_{2} \mathrm{~B}=$ glutardiamidoxime, $\mathrm{HC}=$ glutarimidoxioxime.

Potentiometric and spectrophotometric studies have revealed that the uranyl ion forms the strongest complexes with the cyclic structure, represented here by $\mathrm{H}_{2} \mathrm{~A}$ in Figure 1 (Tian et al., 2012; Pan et al., 2014; Endrizzi et al., 2015). Leggett and Rao (2015b) provide the following overall reaction describing the binding of uranium in seawater with an amidoxime-based polymeric adsorbent:

$$
\mathrm{Ca}_{2}\left[\mathrm{UO}_{2}\left(\mathrm{CO}_{3}\right)_{3}\right]^{0}+2 \mathrm{H}_{2} \mathrm{~A}=\mathrm{UO}_{2}(\mathrm{HA}) \mathrm{A}^{-}+3 \mathrm{HCO}_{3}{ }^{-}+2 \mathrm{Ca}^{2+}
$$

where the amidoxime based ligand $\left(\mathrm{H}_{2} \mathrm{~A}\right)$ grafted to the polymeric adsorbent is represented by glutarimidedioxime, the cyclic amidoxime moiety, the major uranium species in seawater is $\mathrm{Ca}_{2}\left[\mathrm{UO}_{2}\left(\mathrm{CO}_{3}\right)_{3}\right]^{0}$, which is the dominant form at $\mathrm{pH} 8$ (Endrizzi and Rao, 2014; Leggett and Rao, 2015b), and recognition that in seawater at $\mathrm{pH} \sim 8$, the dominant carbonate species is bicarbonate, $\mathrm{HCO}_{3}{ }^{-}$.

Written in this form, it is clear that manipulation of the bicarbonate concentration might be a means to remove uranium from the binding site on the adsorbent. Radically increasing the bicarbonate concentration should shift the equilibria to the left, releasing the uranium to aqueous solution. Because typical bicarbonate concentrations in seawater are in the low millimolar range $(\sim 2 \mathrm{mM})$, it is possible to use a nearly saturated potassium bicarbonate concentration $(\sim 3 \mathrm{M})$ to increase the bicarbonate concentration approximately 1500 -fold over the equilibrium value, providing a significant driving force to shift the equilibrium to the left.

Potassium bicarbonate elution of uranium was initially conceived as a potential elution strategy based on a thermodynamic study of the distribution of uranium species in a bicarbonate solution containing single amidoxime molecules. Thermodynamic data for different uranyl-amidoxime and uranyl-carbonato complexes are all known in the literature (Clark et al., 1995; Tian et al., 2012). Based on the known thermodynamic data of all relevant uranyl species, we employed HySS 2009 software to calculate the distribution of uranyl species in different carbonate solutions at $25^{\circ} \mathrm{C}$ with respect to $\mathrm{pH}$ in the presence of amidoxime molecules $\left(\mathrm{H}_{2} \mathrm{~A}, 0.504 \mathrm{M}\right)$ and uranyl ions $(0.252 \mathrm{M})$. The amidoxime concentration was chosen to be close to that present in the high-surface-area polymer sorbent synthesized by Oak Ridge National Laboratory (ORNL) and the uranium concentration was based on the amount of uranium adsorbed by the polymer sorbent in a simulated seawater adsorption experiment.

Our calculations shown in Figure 2 indicate that in a solution with low bicarbonate concentrations, as in seawater $\left(10^{-3} \mathrm{M}\right)$, virtually all of the uranium ions are bound to the amidoxime molecules. Equation (1) can be reversed, favoring formation of the uranyl tris-carbonato complex if the concentration of bicarbonate becomes significantly high (in the 1 to $3 \mathrm{M}$ range). Figure $2 \mathrm{~b}$ and Figure $2 \mathrm{c}$ show the distribution ratio of $\left[\mathrm{UO}_{2}\left(\mathrm{CO}_{3}\right)_{3}\right]^{4-} / \mathrm{UO}_{2}(\mathrm{HA}) \mathrm{A}^{-}$at $\mathrm{pH} 8.0$ is about $4 / 1$ in $1 \mathrm{M}$ bicarbonate solution and 
increases to $99 / 1$ in $3 \mathrm{M}$ bicarbonate solution. Therefore, with $3 \mathrm{M}$ of bicarbonate concentration, uranyl bound to the amidoxime-based polymer sorbent could be removed from the sorbent into aqueous phase as uranyl tris-carbonato complex.

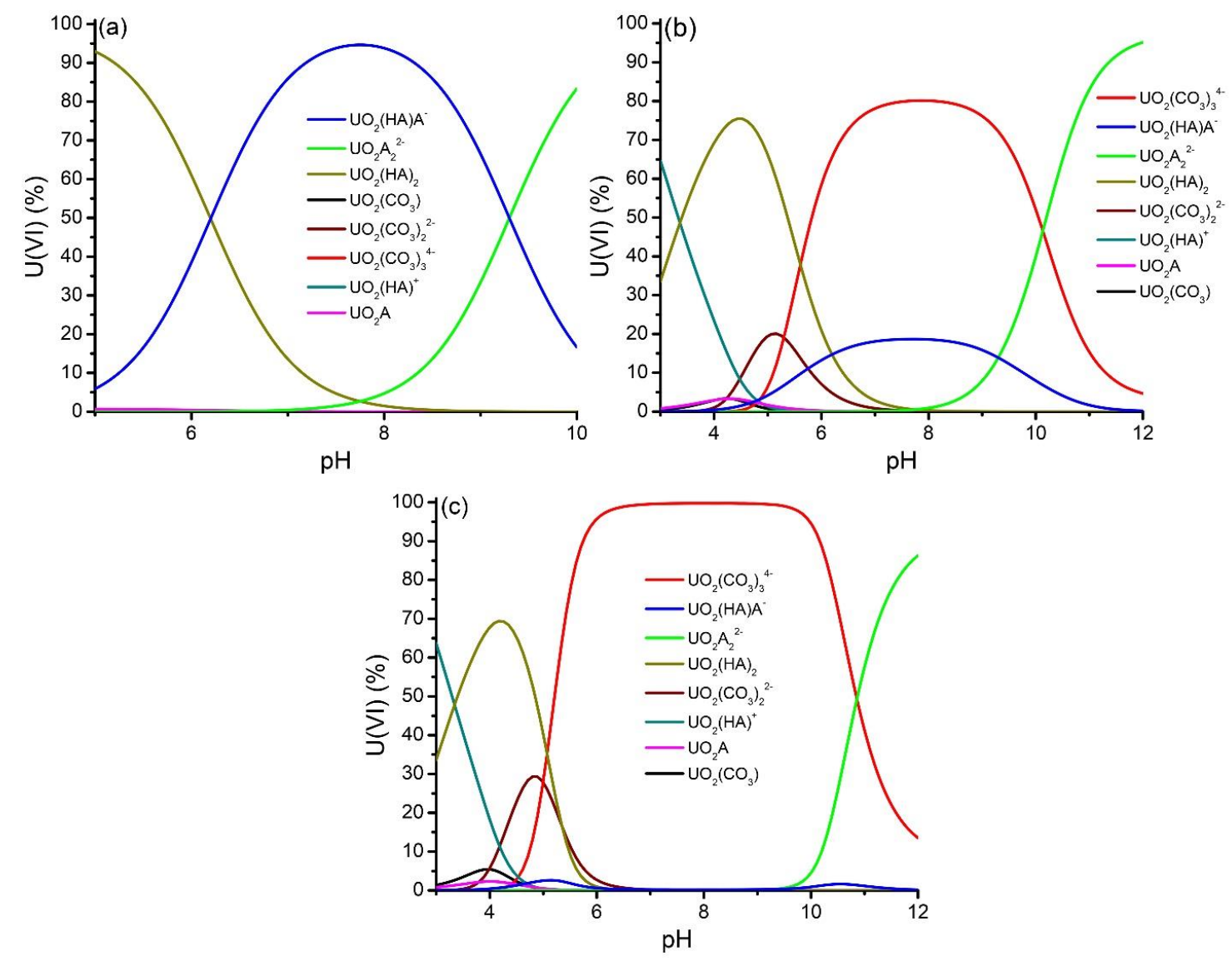

Figure 2. Distribution of uranyl species in water with uranium $(0.252 \mathrm{M})$, single molecule glutarimidedioxime $\left(\mathrm{H}_{2} \mathrm{~A}, 0.504 \mathrm{M}\right)$, and bicarbonate (a) $1 \times 10^{-3} \mathrm{M}$, (b) $1 \mathrm{M}$, and (c) $3 \mathrm{M}$.

According to the $\mathrm{CRC}$ handbook, the solubility of sodium bicarbonate in water is about $1 \mathrm{M}$ at $20^{\circ} \mathrm{C}$ (Figure 3). Therefore, sodium bicarbonate cannot provide a high bicarbonate concentration required for total elution of uranium from amidoxime-based sorbents. However, potassium bicarbonate has solubility in water close to $3 \mathrm{M}$ at $20^{\circ} \mathrm{C}$, and the solubility increases with temperature (Figure 3). Potassium bicarbonate appears to be a good candidate for testing the elution of uranium from the amidoxime-based polymer sorbents. 


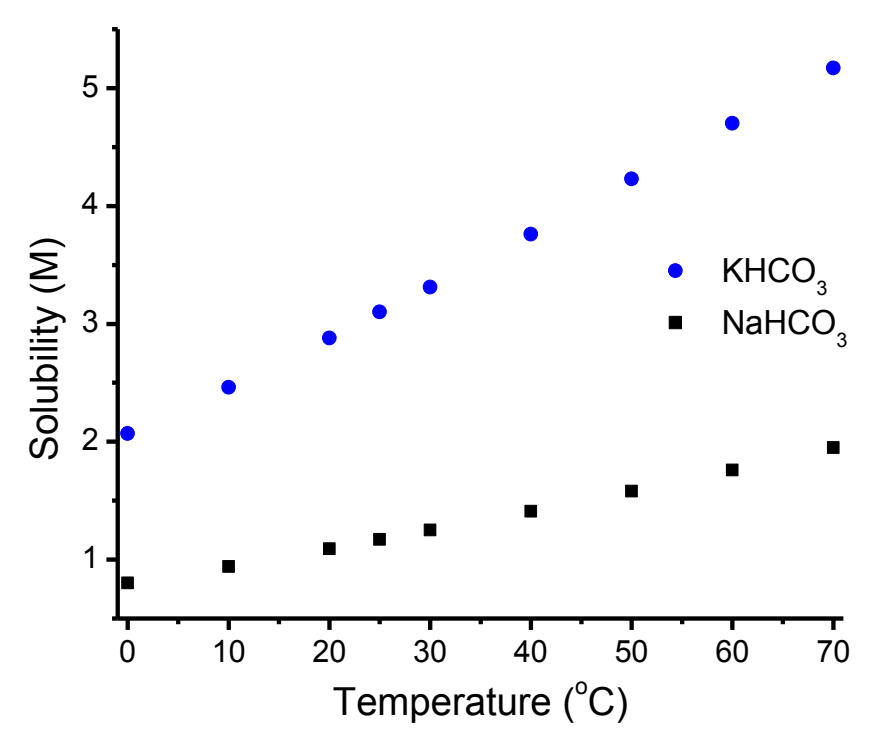

Figure 3. Solubility of $\mathrm{NaHCO}_{3}$ and $\mathrm{KHCO}_{3}$ in water at different temperatures.

\subsection{Experimental Approach}

Amidoxime-based polymeric braid adsorbents were deployed in a flume system exposed to ambient filtered seawater at $20^{\circ} \mathrm{C}$ for a multi-cycle adsorbent reuse study. Three different adsorbent recycling approaches were developed and tested. Adsorption kinetics and adsorption capacity were assessed using time series determinations of uranium adsorption and one-site ligand saturation modeling. Adsorbents were further characterized by spectroscopic and microscopic techniques to investigate potential chemical and physical alterations of adsorbent materials after seawater exposure and adsorbent recycling.

\subsection{PNNL Ambient Seawater Exposure System}

Marine testing was conducted using ambient seawater from Sequim Bay, WA. PNNL's Marine Sciences Laboratory (MSL) has a seawater delivery system that can provide ambient seawater into a "wet laboratory" for scientific investigations. Briefly, ambient seawater is drawn by pump from a depth of $\sim 10 \mathrm{~m}$ from Sequim Bay through a plastic pipe and is passed through an Arkal Spin Klin ${ }^{\mathrm{TM}}$ filter system (nominal pore size $40 \mu \mathrm{m}$ ) to remove large particles. The seawater is then stored in a large volume reservoir tank outside the laboratory. This seawater is fed into the laboratory research facilities at MSL by gravity feed through PVC piping.

Figure 4 and Figure 5 provide a depiction and a picture, respectively, of the manifold system used for seawater exposure of adsorbent materials in flow-through columns. Seawater from the large outside tank is fed sequentially through $5 \mu \mathrm{m}$ and then $1 \mu \mathrm{m}$ cellulose filters and then collected in a $180 \mathrm{~L}$ fiberglass reservoir tank referred to as a "head tank." Seawater in the head tank can be heated to the desired temperature. Temperature-controlled seawater is drawn from the head tank with a pump (non-metallic pump head), passed through a 0.35 to $0.45 \mu \mathrm{m}$ polyethersufone (Memtrex MP, GE Power and Water) or cellulose membrane cartridge filter and into a 24-port PVC manifold. Water that is not used to expose adsorbent material passes through the manifold and is returned to the head tank. Pressure in the manifold 
is controlled with a gate valve at the outlet of the manifold. MSL has four separate 24-port manifolds, linked to three separate head tanks, permitting testing of 96 adsorbent materials in flow-through columns simultaneously.

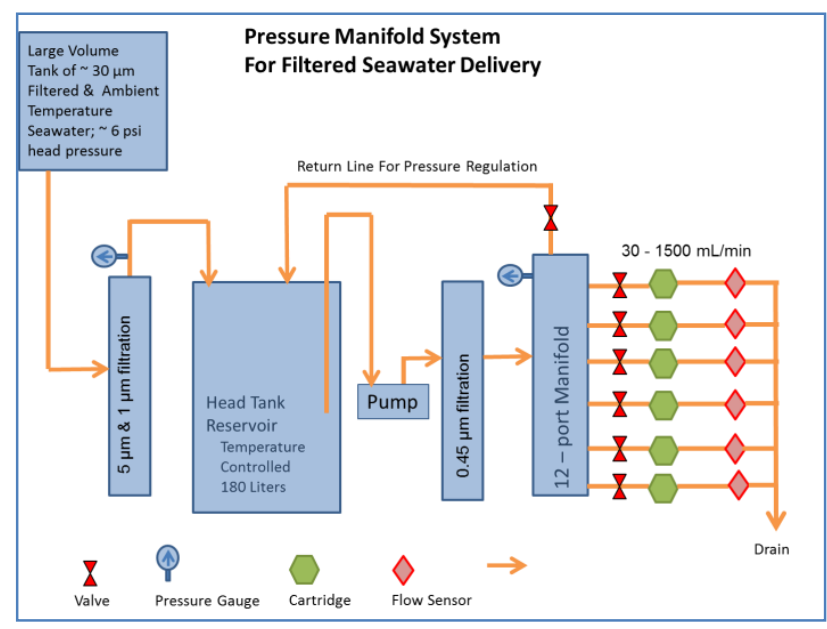

Figure 4. Layout and components of seawater manifold system for exposing uranium adsorbents to ambient seawater.

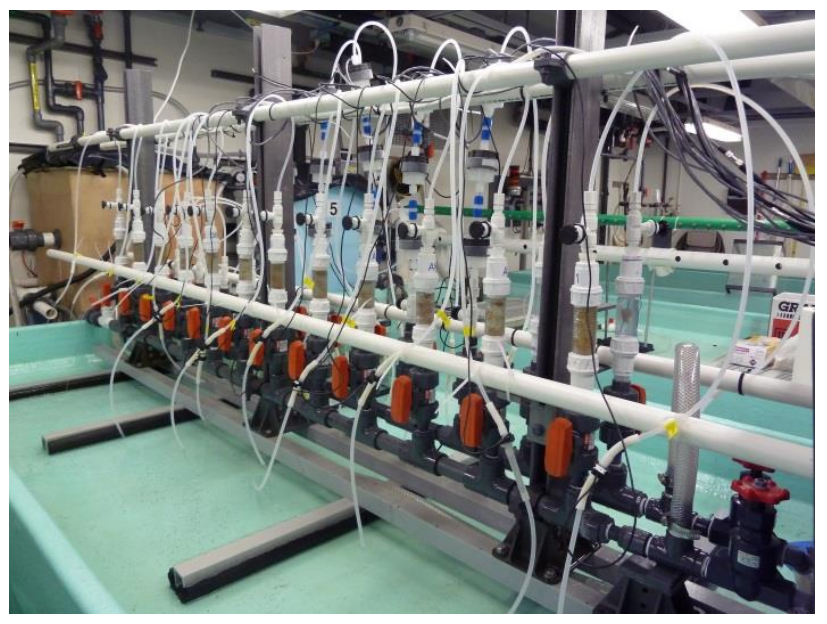

Figure 5. 12-port seawater manifold and PNNLstyle flow-through columns containing uraniumadsorbent material.

\subsubsection{Exposure of Braided Adsorbent Material}

PNNL has developed flow-through channels for conducting flume experiments under controlled temperature and flow-rate conditions for conducting exposure tests with braided adsorbent material. Different pump sizes and flume dimensions are used to create a range in flow-rate (linear velocity). The seawater delivery system described above provides fresh filtered (or unfiltered) seawater to the flume at desired temperatures. Three flumes constructed from darkened acrylic with different dimensions are available for flume studies (Table 1). The specific dimensions were selected to allow the researchers to reproduce a range in linear velocities that one might encounter in a coastal marine environment $(<10 \mathrm{~cm} / \mathrm{s})$. The target linear velocity was $2 \mathrm{~cm} / \mathrm{sec}$, which is approximately the linear velocity being used for flow-through column testing conducted at PNNL. Flume $\mathrm{C}$ was constructed after initial testing with flumes $\mathrm{A}$ and $\mathrm{B}$. Flume $\mathrm{C}$ is narrower and shallower than flumes $\mathrm{A}$ and $\mathrm{B}$, which permitted higher linear velocities due to a narrower cross-sectional area. Two additional flumes have recently been built from clear acrylic (to allow light passage) with the dimensions given for flume $\mathrm{C}$ in Table 1.

Table 1. PNNL flume dimensions

\begin{tabular}{cccccc}
\hline Internal & $\begin{array}{c}\text { Length } \\
(\mathrm{cm})\end{array}$ & $\begin{array}{c}\text { Internal } \\
\text { Width } \\
(\mathrm{cm})\end{array}$ & $\begin{array}{c}\text { Target } \\
\text { Internal } \\
\text { Depth } \\
(\mathrm{cm})\end{array}$ & $\begin{array}{c}\text { Cross } \\
\text { Sectional } \\
\text { Area } \\
\left(\mathrm{cm}^{2}\right)\end{array}$ & $\begin{array}{c}\text { Volume } \\
(\mathrm{L})\end{array}$ \\
\hline $\mathrm{A}$ & 122 & 20.3 & 24.8 & 507 & 63 \\
$\mathrm{~B}$ & 244 & 20.3 & 24.8 & 507 & 126 \\
$\mathrm{C}$ & 183 & 15.2 & 20.3 & 304 & 56 \\
\hline
\end{tabular}

Figure 6 shows is a cross-sectional view of the flume's recirculation system and seawater inlet. Pictures of the flumes are shown in Figure 7 through Figure 9. Fresh seawater can be fed into the system 
from a heated $\left(10^{\circ} \mathrm{C}\right.$ to $\left.30^{\circ} \mathrm{C}\right)$ and filtered $(0.45 \mu \mathrm{m})$ storage tank at flow-rates up to $8 \mathrm{~L} / \mathrm{min}$. The nominal flow rate is $2 \mathrm{~L} / \mathrm{min}$ per braid in the flume. The height of water in the flume is controlled by the height of the standpipe, which can be varied between approximately 6 and 10 inches. The nominal height is 9 inches. Water within the system rises until it reaches the height of the standpipe and then spills out of the flume through the standpipe.

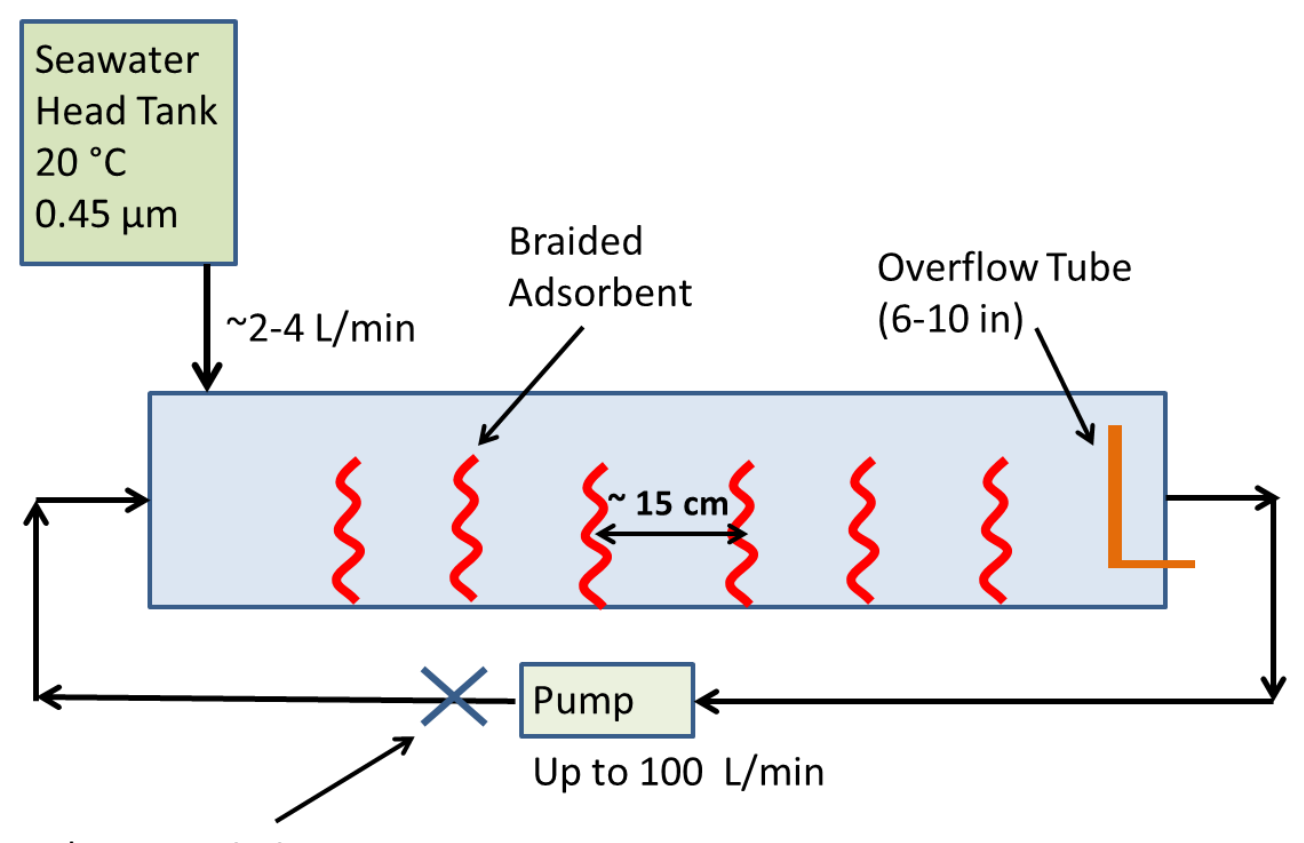

Flow Restriction

Figure 6. Conceptual side view of flume showing fresh seawater inlet and recirculation system.

Controlled water flow within the flume is accomplished by recirculating water using a centrifugal water pump. The pump head is all non-metallic to minimize contamination concerns. A variety of pump sizes are available to achieve the desired flow rates. Finish Thompson pumps (models DB 5, DB6, and DB6H), which have a maximum water delivery rate of 19, 31, and $42 \mathrm{gpm}(74,117$, and $159 \mathrm{~L} / \mathrm{min})$, respectively, with no head are being used. In practice, these pumps delivered about two-thirds of the maximum flow at a pressure of around 6 psi. Precise control of flow-rate/linear velocity was achieved by putting a flow restriction (globe valve) at the outlet of the pump. The flow-rate in the recirculating water was continuously monitored by placing a flow meter (Omega) in the line between the flume outlet and pump inlet.

The linear velocity in the tank was determined using the cross-sectional area of the tank and the recirculation flow-rate. For example, a linear velocity of $2 \mathrm{~cm} / \mathrm{s}$ was achieved in the 6 foot flume with a $20.3 \mathrm{~cm}$ water height (cross-sectional area of $300 \mathrm{~cm}^{2}$ ) using the lower capacity pump and setting the flow-rate to $9 \mathrm{gpm}(34 \mathrm{~L} / \mathrm{min})$. There is a slight increase in linear velocity ( 9\%) due to the fresh seawater inflow of $3 \mathrm{~L} / \mathrm{min}$, but it is small relative to the recirculation flow of $34 \mathrm{~L} / \mathrm{min}$. 


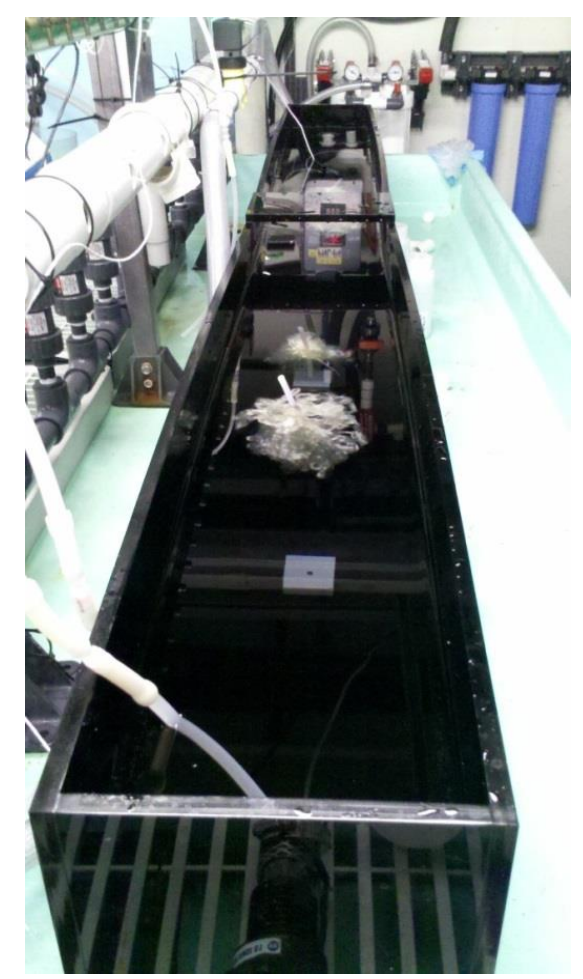

Figure 7. Eight-foot flume with adsorbent material in place for marine testing. Water recirculation is turned off for the picture.

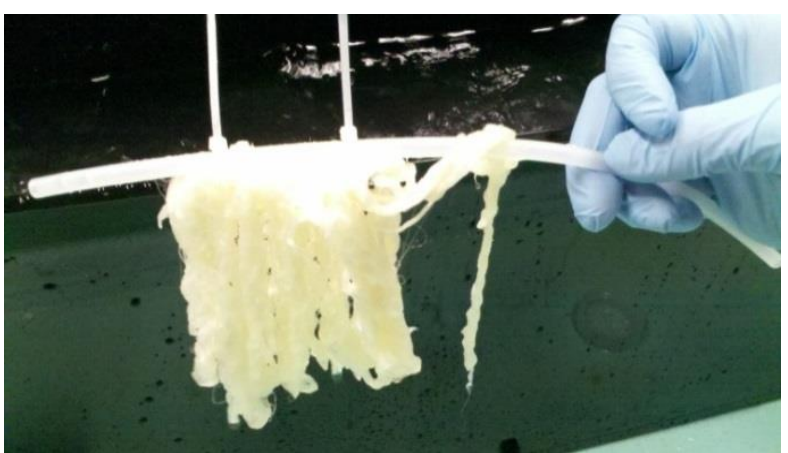

Figure 8. Adsorbent braid attached to a short length of 1/4-inch polyethylene tubing. The tubing is then inserted into a block attached to the bottom of the flume (see Figure 7).

The rate at which water is fed into the system and the internal volume of the flume controls the residence time of new water in the system. For the above example with the $6 \mathrm{ft}$ flume, the water residence time is 18.9 minutes. The time to recirculate water is much faster. At a recirculation flow rate of $34 \mathrm{~L} / \mathrm{min}$, the water in the flume is recirculated once every 1.7 minutes. Hence, the water in the flume is well mixed.

Using a pump with an unrestricted flow capacity of $42 \mathrm{gpm}(160 \mathrm{~L} / \mathrm{min})$, and the narrower flume with an internal depth of 6 inches $(15.2 \mathrm{~cm})$, a maximum linear velocity of $11.7 \mathrm{~cm} / \mathrm{sec}$ can be achieved. In practice, the flow would likely be about two-thirds of the unrestricted flow, yielding a linear velocity of $\sim 7.7 \mathrm{~cm} / \mathrm{s}$. Adding fresh seawater at $\sim 3 \mathrm{~L} / \mathrm{min}$ would increase the linear velocity to approximately $8.1 \mathrm{~cm} / \mathrm{s}$. Hence, a range of linear velocities is possible that would mimic currents in the coastal ocean reasonably well. 


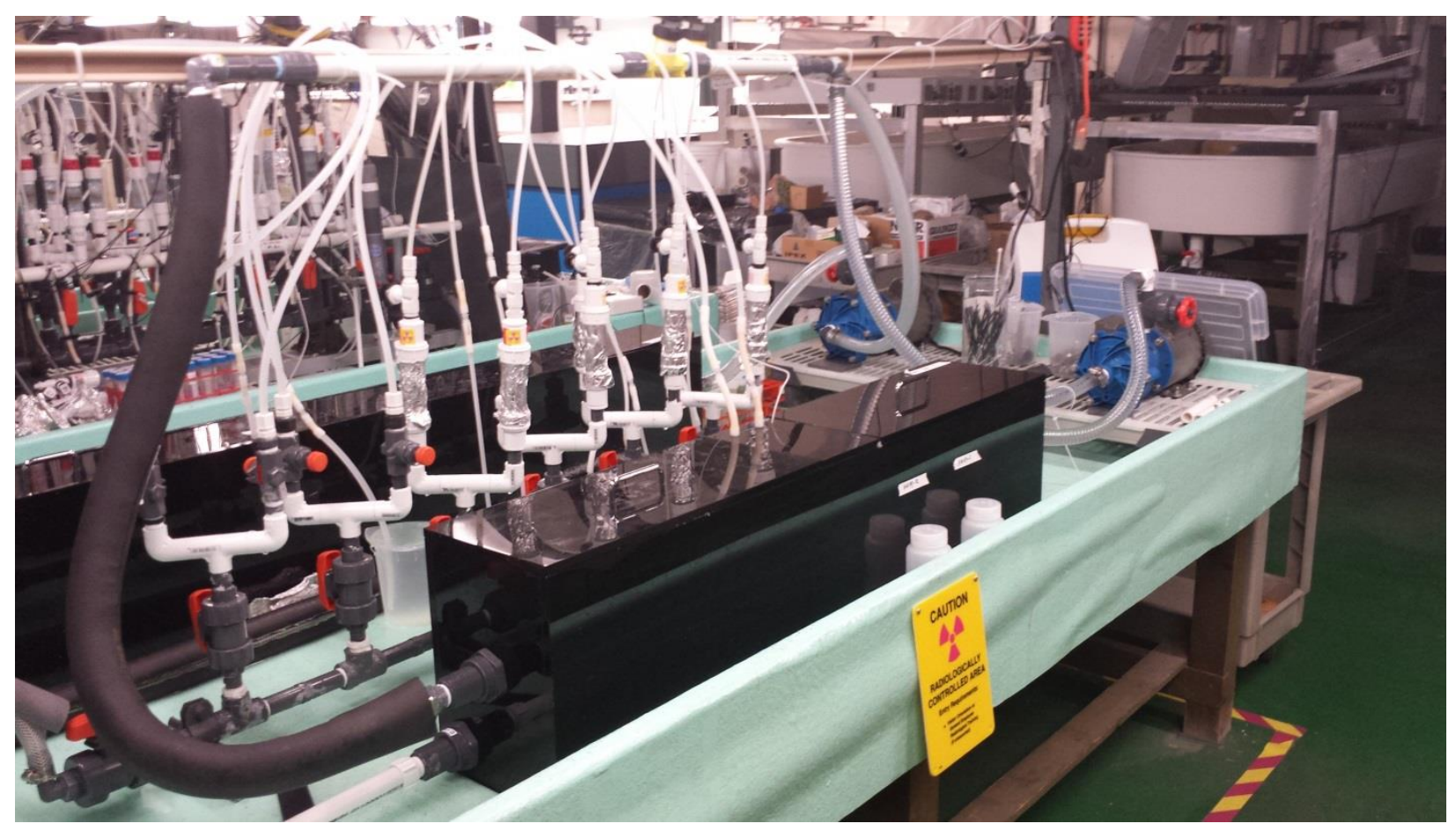

Figure 9. Four-foot flume. The recirculation pump is on the right-hand side. Recirculated water passes through the flow meter (yellow section of piping) and water flow is controlled by the (red) valve at outlet of the pump. Fresh seawater inflow is delivered from the manifold (behind the flume) through poly tubing inserted through the top of the flume lid.

\subsubsection{One-Site Ligand Saturation Modeling}

The binding of the uranyl ion to the amidoxime-based polymeric adsorbent was evaluated using a one-site ligand saturation model, which was parameterized using the software graphics program SigmaPlot $\odot$. The best-fit line representing the time series adsorption of uranium is given by:

$$
u=\frac{\beta_{\max } t}{K_{d}+t}
$$

Where $u$ is uranium capacity (g U/kg adsorbent), $t$ is exposure time (days), $\beta_{\max }$ is the adsorption capacity at saturation (g U/kg adsorbent), and $K_{d}$ is the half-saturation time (days).

\subsection{Recycling Approaches for Reuse of Amidoxime-Based Uranium Adsorbents}

For uranium adsorbents to be used repeatedly, it is important to have a recycling approach that can effectively strip off uranium from the adsorbents without causing a negative impact to the uranium adsorption capability of the adsorbents. A typical approach to recovering uranium adsorbents is acid elution (e.g., HCl) (Suzuki et al., 2000; Seko et al., 2005; Pan et al., 2014). However, it is also known that acid elution, especially under relatively high acid concentration, can deteriorate the adsorbent due to acid hydrolysis of amidoxime groups (Pan et al., 2014). Alternative mild uranium stripping approaches were thus developed for uranium adsorbent reuse (Pan et al., 2014; Pan et al., 2015). 
In the present study, we developed and evaluated the effectiveness of a bicarbonate elution method. We also tested a modified version of the bicarbonate elution method that includes one extra Tiron elution step to further remove iron, one strong competing ion for binding with amidoxime groups. The traditional acid elution method was also reevaluated and used for comparison. A detailed description of the three elution approaches follows.

\subsubsection{Recycling Approach I: Acid Elution}

A preliminary study of $\mathrm{HCl}$ elution on an ORNL amidoxime-based polymeric adsorbent (ORNL ID: 38H6) was conducted to investigate the optimal acid concentration and elution time for stripping uranium and other trace elements from the adsorbent. As shown in Figure 10, uranium can be totally stripped off the adsorbent by $1 \mathrm{M} \mathrm{HCl}$ in 90 minutes at room temperature. These conditions also removed $>95 \%$ of the $\mathrm{Ni}, \mathrm{Cu}, \mathrm{Zn}$, and $\mathrm{Fe}$ from adsorbent (Figure 11). When the $\mathrm{HCl}$ concentration is decreased to $0.5 \mathrm{M}$, $>95 \% \mathrm{U}, \mathrm{Ni}, \mathrm{Cu}$, and $\mathrm{Zn}$ and $>70 \% \mathrm{Fe}$ can be removed from the adsorbent. Vanadium (V) can only be partially stripped from the adsorbent with elevated $\mathrm{HCl}$ concentration $(>3 \mathrm{M}$ ) and temperature (e.g., $60^{\circ} \mathrm{C}$ ). However, under such severe acid treatment, the adsorbent is virtually destroyed. Since $1 \mathrm{M} \mathrm{HCl}$ was also reported to cause adsorbent damage (Pan et al., 2014), we adopted $0.5 \mathrm{M} \mathrm{HCl}$ and 90 min elution at room temperature as the elution condition for this adsorbent recycling study.

It is important to note that after acid elution, the amidoxime-based polymeric adsorbents need to be reconditioned by alkaline solution (e.g., $2.5 \% \mathrm{KOH}$ at $80^{\circ} \mathrm{C}$ ) (Pan et al., 2014). During the initial base conditioning, the adsorbent forms a hydrogel. Subsequent acid treatment to remove adsorbed elements collapses the hydrogel and protonates the carboxylic acid and amidoxime. This permits strong hydrogen bonding to occur and makes the adsorbent hydrophobic. The additional alkaline treatment is thus necessary to regenerate the hydrophilicity of the adsorbent for uranium adsorption experiments.

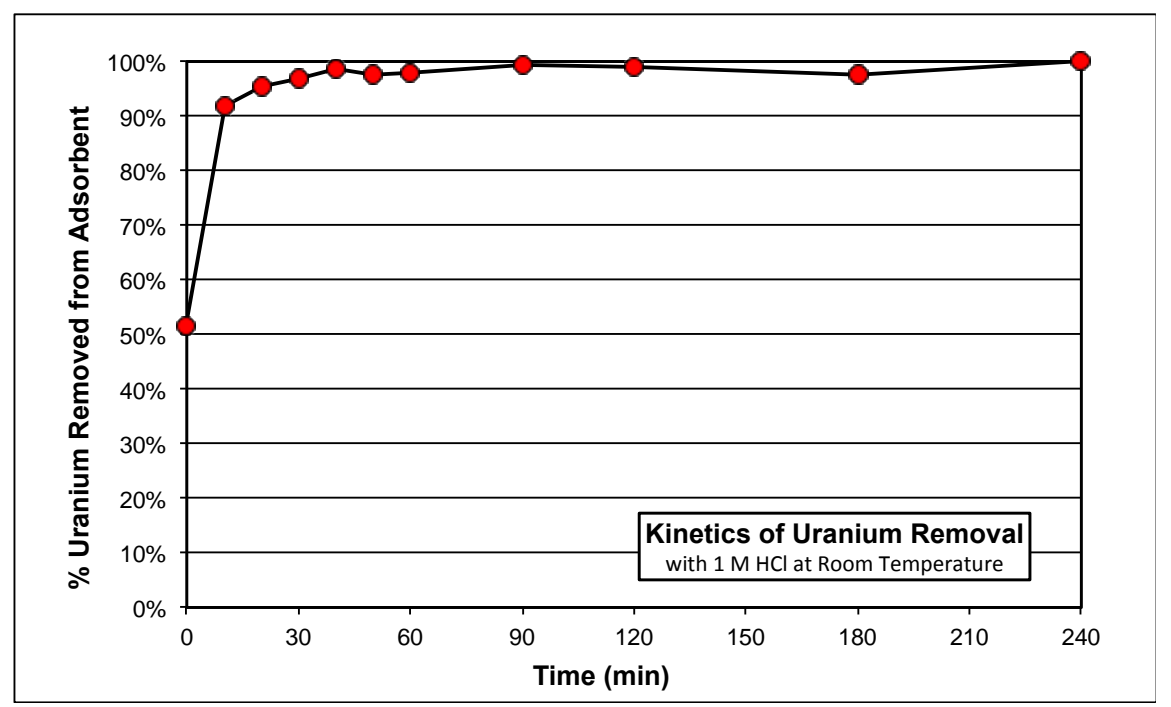

Figure 10. Kinetics of uranium removal from ORNL adsorbent $38 \mathrm{H} 6$ using $1 \mathrm{M} \mathrm{HCl}$ at room temperature. 


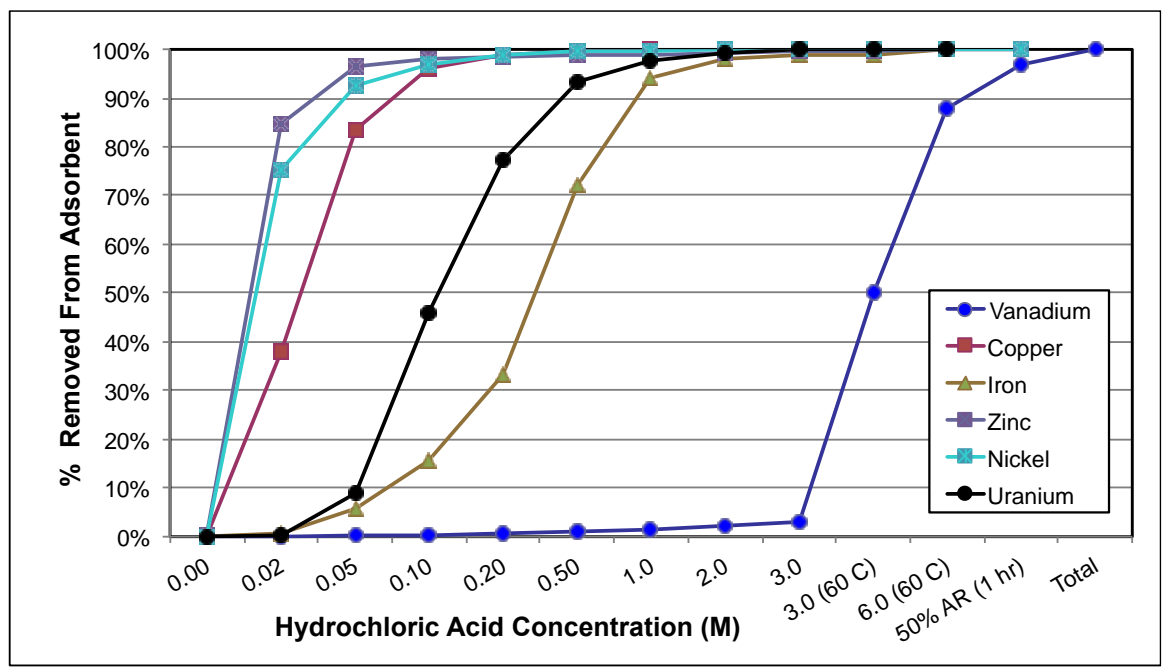

Figure 11. Kinetics of uranium and transition metals removal from ORNL adsorbent 38H6 using $1 \mathrm{M}$ $\mathrm{HCl}$ at room temperature.

\subsubsection{Recycling Approach II: Bicarbonate Elution}

To test desorption of uranium from the high-surface-area amidoxime-grafted polymer sorbents, we first performed uranium adsorption experiments in simulated seawater spiked with uranium (9 ppm) using the procedure we recently reported in the literature (Pan et al., 2014). The uranium elution experiments were performed using different concentrations of potassium bicarbonate solutions at different temperatures, and the results are given in Figure 12.

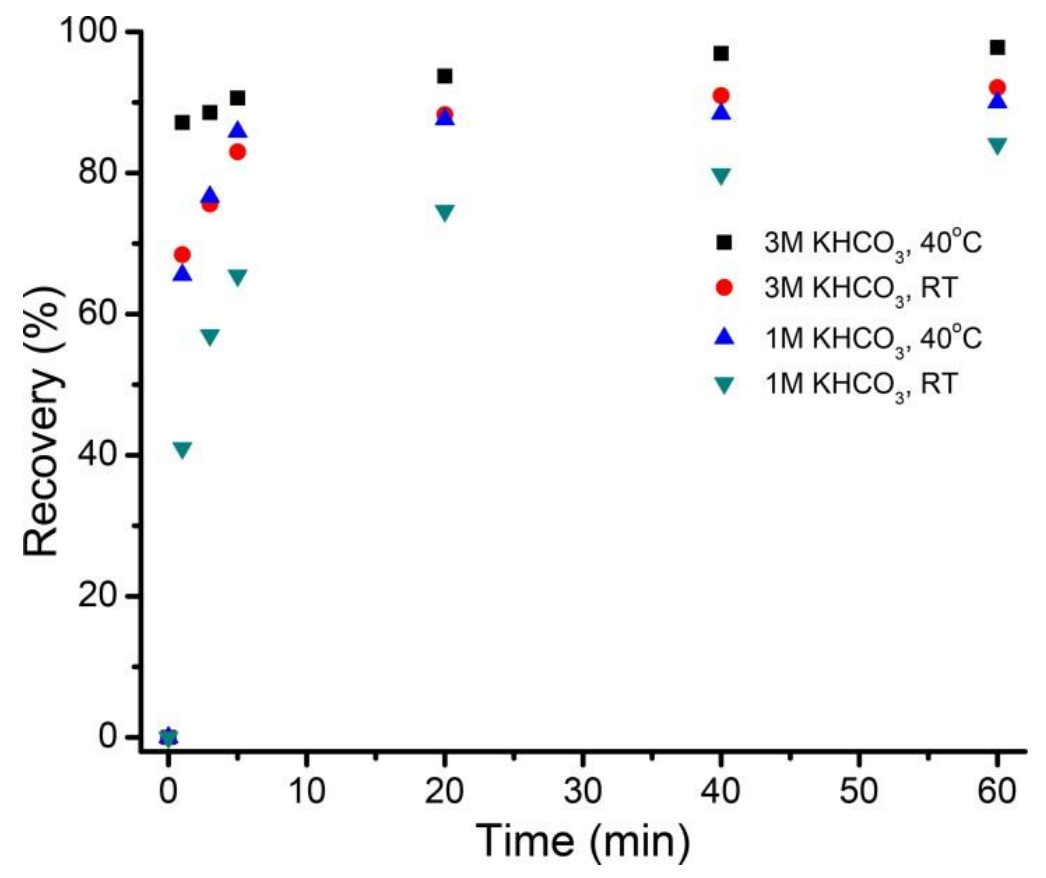

Figure 12. Rates of uranium elution from the sorbent at different temperatures and bicarbonate concentrations.

About $92 \%$ of uranium can be eluted from the sorbent at room temperature $\left(21^{\circ} \mathrm{C}\right)$ in $3 \mathrm{M}$ potassium bicarbonate solution (Figure 12). When the temperature is raised to $40^{\circ} \mathrm{C}$, near total elution of uranium 
with $3 \mathrm{M}$ potassium bicarbonate can be achieved within 1 hour. The $\mathrm{pH}$ of a $3 \mathrm{M}$ bicarbonate solution is about 8.2, very close to typical seawater $\mathrm{pH}$. For $\mathrm{KHCO}_{3}$ elution, no $\mathrm{KOH}$ reconditioning is required for its reuse. After bicarbonate elution, the sorbent is rinsed with deionized water several times for the second cycle of the adsorption-elution experiment. The potassium bicarbonate elution method causes virtually no reduction in uranium adsorption capacity of the amidoxime-based fiber sorbent after 6 cycles of repeated adsorption-desorption processes in simulated seawater spiked with uranium (9 ppm).

\subsubsection{Recycling Approach III: Bicarbonate Elution Followed by Tiron Elution}

If $\mathrm{KHCO}_{3}$ elution selectively removes uranium from amidoxime-based adsorbents, there will remain on the adsorbent a suite of other metals that occupy sites in competition with uranium. Previous experiments at PNNL have shown that iron and vanadium are two transition metals that have significant abundance on the adsorbent and moreover are known to compete with uranium for adsorption to amidoxime-based adsorbents (Sun et al., 2013; Kim et al., 2014). Hence, it would be desirable to remove these metals prior to adsorbent reuse. One approach would be to use a targeted chelating ion exchange ligand to remove competitive metals. We tested a number of chelating agents for removing vanadium and iron from the amidoxime-based sorbents (Table 2).

Table 2. Elution of Fe and V from amidoxime-based polymeric sorbents by different metal chelating ligands. ${ }^{(a)}$

\begin{tabular}{|c|c|c|c|}
\hline $\begin{array}{l}\text { Chelating } \\
\text { Ligand }^{(b)}\end{array}$ & $\mathrm{pH}$ & \% Iron Removed from Sorbent & $\%$ Vanadium Removed from Sorbent \\
\hline $0.5 \mathrm{M}$ Tiron & 12.59 & 83.4 & 6.1 \\
\hline $0.5 \mathrm{M}$ Tiron & 7.17 & 94.0 & 7.0 \\
\hline $0.5 \mathrm{M}$ Tiron & 3.36 & 36.6 & 0.3 \\
\hline $1 \mathrm{M}$ TSCIT & 7.98 & 29.6 & 0.0 \\
\hline $1 \mathrm{M} \mathrm{TSCIT}^{(\mathrm{c})}$ & 6.42 & 84.9 & 4.3 \\
\hline $1 \mathrm{M}$ TRIS & 4.41 & 61.2 & 1.5 \\
\hline $1 \mathrm{M} \mathrm{TRIS}^{(\mathrm{c})}$ & 4.50 & 69.0 & 1.0 \\
\hline 1 M EDTA & 10.73 & 0.0 & 0.0 \\
\hline 1M DTPA & 12.71 & 0.0 & 0.0 \\
\hline
\end{tabular}

(a) Leaching condition: at $40^{\circ} \mathrm{C}$ for $24 \mathrm{hr}$.

(b) Tiron = 4,5-Dihydroxy-1,3-benzenedisulfonic acid disodium salt; TSCIT = Trisodium citrate dehydrate; TRIS = Nitrilotris(methylene)triphosphonic acid; EDTA $=$ Ethylenediaminetetraacetic acid; DTPA = Diethylene triamine pentaacetic acid.

(c) Adding $0.1 \mathrm{M}$ Tiron.

Our results indicate that Tiron (4,5-Dihydroxy-1,3-benzenedisulfonic acid disodium salt) can elute iron from the amidoxime-based sorbent very effectively at $\mathrm{pH}$ around 7. Moreover, Tiron also removes some vanadium from the sorbent. The Fourier transform infrared spectroscopy (FTIR) spectra shown in Figure 13 indicate that after the Tiron elution, both the 1643 and $928 \mathrm{~cm}^{-1}$ wavelengths remain unchanged, suggesting that the functional groups of the sorbent are unaltered. The decrease in the carboxylate intensity most likely results from the protonation of some carboxylate anions at the elution $\mathrm{pH}$ of approximately 7. How this treatment affects adsorbent swelling is not clear. Since Tiron does not change the structures of the functional groups, no $\mathrm{KOH}$ reconditioning is necessary for adsorbent reuse after the Tiron treatment. Other chelating agents were not so effective for removing iron from the amidoximebased sorbents. Therefore, Tiron was chosen for leaching iron from the sorbents (ORNL-AF1 and Japanese sorbents) in real seawater experiments. 


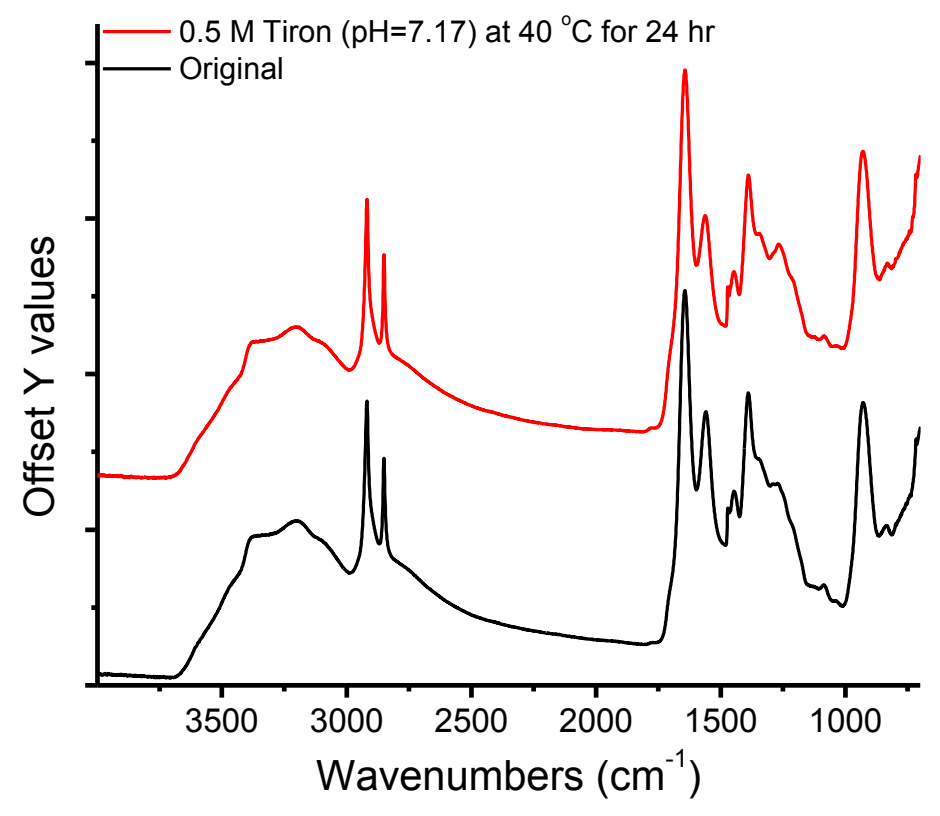

Figure 13. FTIR spectra of the ORNL-AF1 amidoxime-based polymeric adsorbent before and after Tiron elution.

\subsection{Preparation of Amidoxime-based Polymeric Adsorbent Braids}

Three amidoxime-based, high-surface area polyethylene fibrous braids in AF1 formulation (AF1L2R3) were prepared by Chris Janke at ORNL using the radiation-induced graft polymerization (RIGP) method (Kim et al., 2013, 2014; Janke et al., 2013). The RIGP method involves four processing steps: (1) electron beam irradiation of high surface area polyethylene fibers, (2) co-grafting polymerizable monomers containing nitrile groups and hydrophilic groups to form grafted side chains throughout the fiber, (3) conversion of nitrile groups to amidoxime groups, and (4) alkaline conditioning of the grafted fibers.

Grafted braid materials were shipped dry to PNNL and were conditioned immediately before the seawater exposure. The conditioning procedure consisted of gently stirring the fibers in a $2.5 \%(\sim 0.44$ M) potassium hydroxide $(\mathrm{KOH})$ solution at $80^{\circ} \mathrm{C}$ for 1 hour. One milliliter of the $\mathrm{KOH}$ solution was used per milligram of adsorbent material. Due to the large size of braid material (up to $7 \mathrm{~g}$ ), the braids were conditioned in a carboy and heated using an incubated shaker (Thermo Scientific MaxQ ${ }^{\mathrm{TM}}$ 6000). Immediately after conditioning, the braids were rinsed several times with deionized water until neutral $\mathrm{pH}$ was reached. The conditioned braids were stored in a pre-cleaned HDPE bottle filled with deionized water until placed in the flume for natural seawater exposure.

\subsection{Multi-cycle Adsorbent Reuse Test}

A multi-cycle adsorbent reuse test was conducted using the braided material provided by ORNL (described above), with natural seawater exposure using the PNNL flume system described previously. The seawater exposure duration for each cycle was 42 days. A flow chart describing the experiment is given in Figure 14. The procedure includes initial seawater exposure (42 days), then the elution of the seawater-exposed braids to remove uranium and other trace elements, followed reexposure to seawater for 
another 42 days, and so on. During the seawater exposure, a "snip" of approximately $100 \mathrm{mg}$ of adsorbent fiber was taken from each braid at time points 7, 14, 21, 28, and 42 days using a pair of titanium-coated scissors. These time series subsamples provide the sorption kinetics information of uranium and other trace elements. Furthermore, we sampled some adsorbent fibers in every major adsorbent treatment step, including before and after $\mathrm{KOH}$ conditioning, after each cycle of 42-day seawater exposure, and after each recycling treatment.

Prior to the initial elution of the AF1 adsorbent, a separate 42-day exposed sample was used to confirm the elution kinetics with the three elution methods to verify that the elution times were appropriate to achieve full recovery.

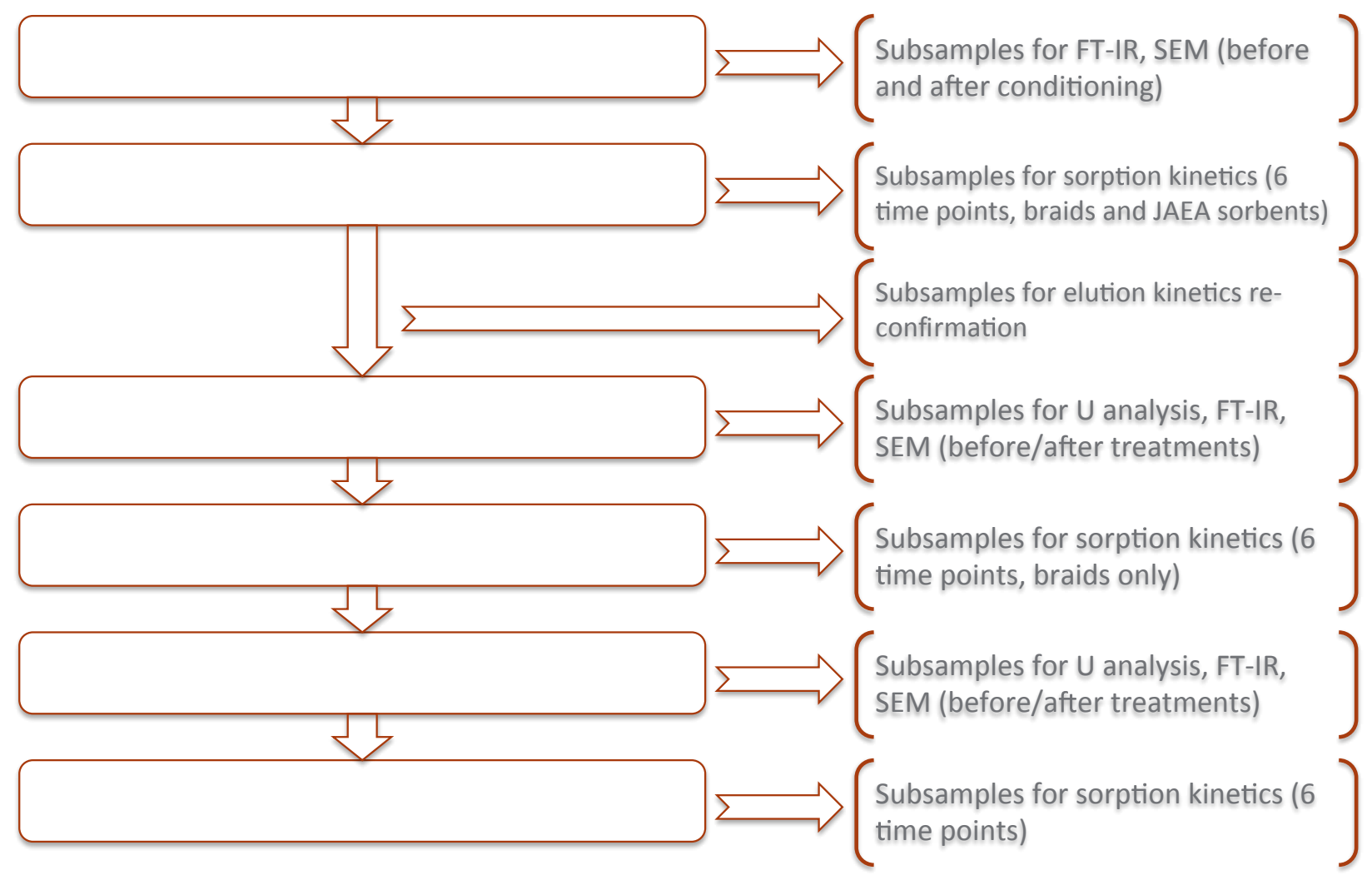

Figure 14. Experimental design of the steps involved in a multi-cycle adsorbent reuse test.

\subsubsection{Flume Operation}

The $122 \mathrm{~cm}$ ( $4 \mathrm{ft}$ ) length by $20.3 \mathrm{~cm}$ ( 8 inches) width opaque flume was used in this study (Table 1). The water depth in the flume was held at $22.9 \mathrm{~cm}$ (9 inches), making the total volume in the flume $57 \mathrm{~L}$. The flow rate of fresh filtered seawater was introduced at $3 \mathrm{~L} / \mathrm{min}$. The seawater recirculation pump was adjusted to $50 \mathrm{~L} / \mathrm{min}$. The combination of the introduction of fresh seawater and recirculated seawater produced a linear velocity of $1.9 \mathrm{~cm} / \mathrm{sec}$. Seawater temperature was controlled at $20^{\circ} \mathrm{C}$. The temperature of the seawater in the flume was monitored and recorded every 5 minutes using an Omega model HH804U handheld meter equipped with a long lead and non-metallic temperature probe. Data was recorded and stored by attaching the meter to a laptop computer. 


\subsubsection{Water Quality Measurements}

Salinity and $\mathrm{pH}$ measurements were conducted daily. Salinity was determined using a handheld YSI salinometer. The $\mathrm{pH}$ was measured with a standard $\mathrm{pH}$ meter and probe that was calibrated weekly using NIST-traceable buffers.

\subsubsection{Characterization of Adsorbents}

All samples were characterized dry with FTIR and a scanning electron microscope (SEM), in addition to trace element analysis. These determinations provide valuable information on potential alterations of surface functional groups and physical state of adsorbent (morphology) during different treatments and repeated seawater deployment.

\subsubsection{Determination of Uranium and Trace Elements on Adsorbent Materials}

Adsorbent materials exposed to seawater were washed with deionized water to remove salts, and the monitoring the process with a conductivity meter. Samples were then dried at $80^{\circ} \mathrm{C}$ to a constant weight using a heated block (ModBlock ${ }^{\mathrm{TM}}$, CPI International). The dried fibers (50 to $100 \mathrm{mg}$ ) were weighed and then digested with $10 \mathrm{~mL}$ of a high-purity (Optima Grade, Fisher Scientific) 50\% aqua regia acid mixture (3:1; hydrochloric acid: nitric acid) for 3 hours at $85^{\circ} \mathrm{C}$ on a hot block. Analysis of uranium and other trace elements was conducted using either a Perkin-Elmer 4300 inductively coupled plasma optical emission spectrometer or a Thermo Scientific ICap ${ }^{\mathrm{TM}} \mathrm{Q}$ inductively coupled plasma mass spectrometer. Quantification with both instruments is based on standard calibration curves.

\subsubsection{Determination of Uranium in Seawater}

Determination of uranium in natural seawater samples was conducted using inductively coupled plasma mass spectrometry and the method of standard addition calibrations. Addition calibration is a variant of the standard additions method and is often used when all samples have a similar matrix. Instrumental calibration curves were prepared in Sequim Bay seawater that was diluted 20-fold with high purity deionized water and then spiked at four different concentration levels: $0.1,0.2,0.3$, and $0.4 \mu \mathrm{g} / \mathrm{L}$, along with a $2 \%$ nitric acid blank in the diluted seawater. The seawater samples were then analyzed at 20 -fold dilution with high purity deionized water and then quantified using the matrix matched additions calibration curve. The standard reference material CASS-5 (Nearshore Seawater Reference Material for Trace Metals) available from the National Research Council Canada, which is certified for uranium (3.18 $\pm 0.10 \mu \mathrm{g} / \mathrm{L}$ ), was also analyzed at a 20 -fold dilution every 10 samples to verify the analytical results. The uranium recovery for the analysis of CASS-5 ranged from $93 \%$ to $99 \%(n=9)$. Duplicate analyses and matrix spikes were conducted with each batch of samples. The relative percent difference for duplicates ranged from $1 \%$ to $5 \%$, and the recovery of matrix spikes ranged from $93 \%$ to $109 \%(\mathrm{n}=11)$.

\subsubsection{Fourier Transform Infrared Spectroscopy (FTIR) Analysis}

FTIR spectra were acquired on dry samples using a Nicolet Magna 760 FTIR spectrometer equipped with a deuterated tri glycine sulfate (DTGS) detector. FTIR measurements were made with a SplitPea attenuated total reflection accessory (Harrick Scientific Corporation) along with a silicon internal reflection element used as a reflection medium. High resolution FTIR spectra in the range of 4000 to 700 $\mathrm{cm}^{-1}$ were acquired using 500 co-added scans at $2 \mathrm{~cm}^{-1}$ resolution with Norton-Beer "medium" 
apodization function. The spectra were normalized to the $2918 \mathrm{~cm}^{-1}$ peak, the C-H stretch of the polyethylene, to facilitate comparison.

\subsubsection{SEM Analysis}

Microscopic morphologies of the high-surface-area amidoxime-based polymer fiber adsorbents were investigated by field emission gun scanning electron microscopy (Zeiss Supra 35 SEM). All samples were coated with a thin layer of carbon for the SEM observations to prevent charging effects and damage to the sample at $5 \mathrm{kV}$ operating voltage.

\subsection{Results}

\subsection{Reevaluation of Elution Kinetics and Efficiency}

After the initial 42-day seawater exposure, some adsorbent fibers were cut from AF1L2R3 braid for elution kinetics reevaluation (Figure 15 through Figure 17). Included in these tests were two amidoximebased, non-woven adsorbent materials (JAEA-sa, JAEA-ia) obtained from the Japan Atomic Energy Agency (JAEA) in 2014. The reevaluation confirmed that $0.5 \mathrm{M} \mathrm{HCl}$ can completely remove uranium from the ORNL adsorbent AF1L2R3 and the two JAEA adsorbents in 1 hour (Figure 15). The milder leaching method using $3 \mathrm{M} \mathrm{KHCO}_{3}$ requires more than 20 hours to completely remove uranium from the ORNL adsorbent AF1L2R3, but just needs 1 hour to strip uranium off the JAEA adsorbents (Figure 16). A $0.5 \mathrm{M}$ Tiron solution at $\mathrm{pH} 7.0$ can quickly remove iron from both the ORNL AF1L2R3 and the two JAEA adsorbents in 1 hour (Figure 17).

Based on these results, the finalized elution conditions for the three leaching methods are listed in Table 3. Longer elution time is adopted for leaching of braid materials because previous leaching tests used only using small quantities $(\sim 50 \mathrm{mg})$ of adsorbent fibers.

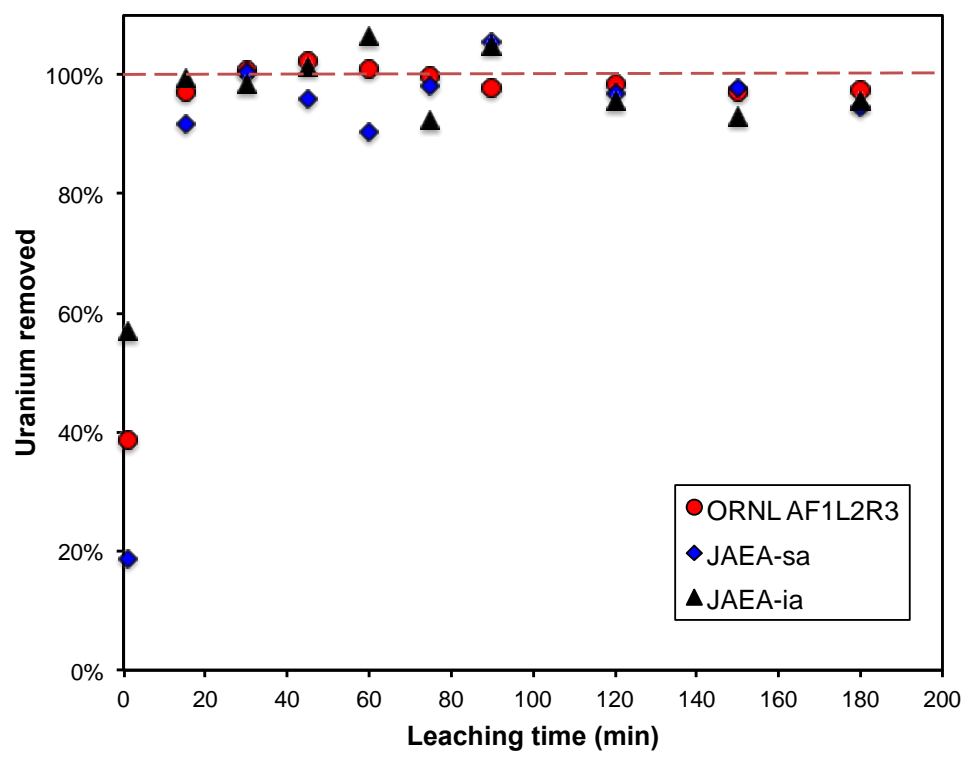

Figure 15. Uranium leaching kinetics from different adsorbents using $0.5 \mathrm{M} \mathrm{HCl}$ solution at room temperature. 


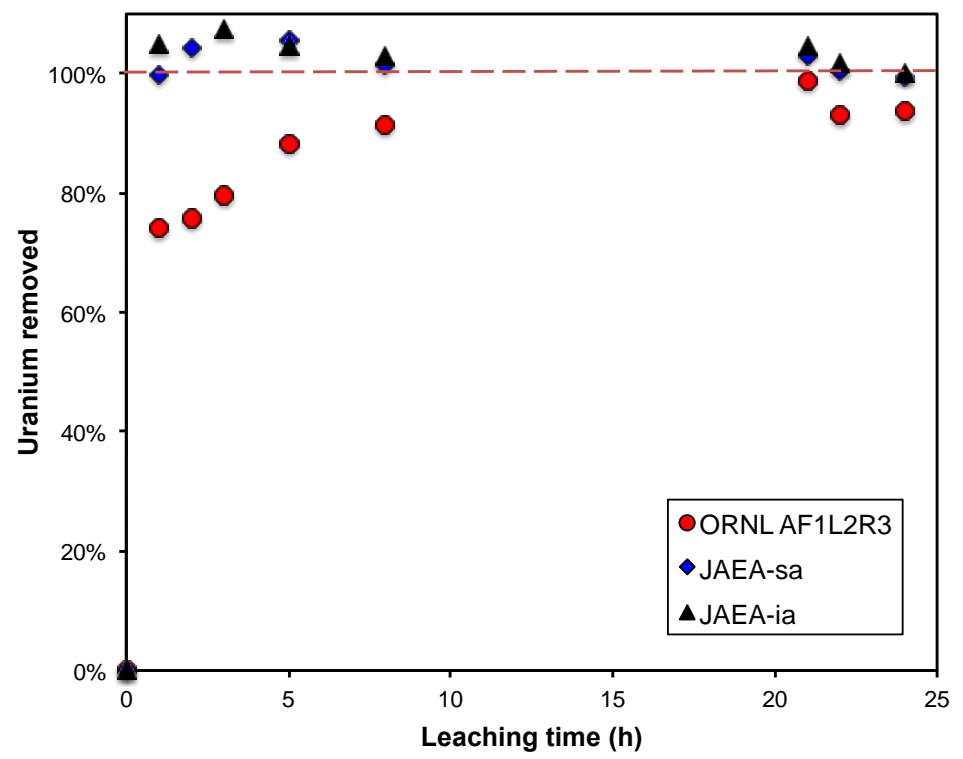

Figure 16. Uranium leaching kinetics from different adsorbents using $3 \mathrm{M} \mathrm{KHCO}_{3}$ solution at $40^{\circ} \mathrm{C}$.

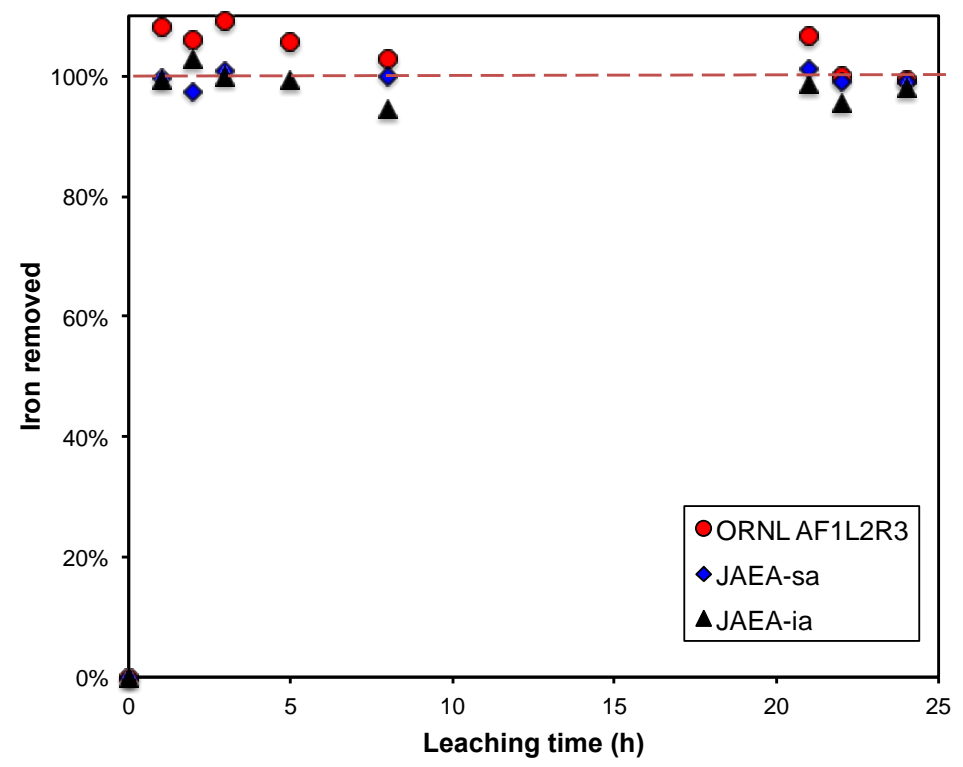

Figure 17. Iron leaching kinetics from different adsorbents using $0.5 \mathrm{M}$ Tiron solution at $40^{\circ} \mathrm{C}$.

Table 3. Finalized elution conditions for the three elution methods.

\begin{tabular}{cccc}
\hline Elution reagent & Target element & $\begin{array}{c}\text { Temperature } \\
\left({ }^{\circ} \mathrm{C}\right)\end{array}$ & $\begin{array}{c}\text { Duration } \\
(\mathrm{h})\end{array}$ \\
\hline $\mathrm{HCl}$ & Uranium & $\mathrm{RT}$ & 1 \\
$\mathrm{KHCO}_{3}$ & Uranium & 40 & 24 \\
Tiron $(\mathrm{pH} 7)$ & Iron & 40 & 4 \\
\hline
\end{tabular}




\subsection{Adsorbent Recycle Experiment - Initial Seawater Exposure}

Figure 18 summarizes the time-dependent measurements of uranium adsorption kinetics on three identical ORNL AF1L2R3 braids used for testing different recycling approaches. Adsorption kinetics were modeled using the one-site ligand saturation modeling. Half-saturation time and saturation capacity information obtained from the one-site ligand saturation modeling of the experimental data are given in Table 4. In general, there is no significant difference between the uranium sorption kinetics and saturation capacity for the three braids. This feature is crucial in this test if comparison between the elution processes is to be valid.

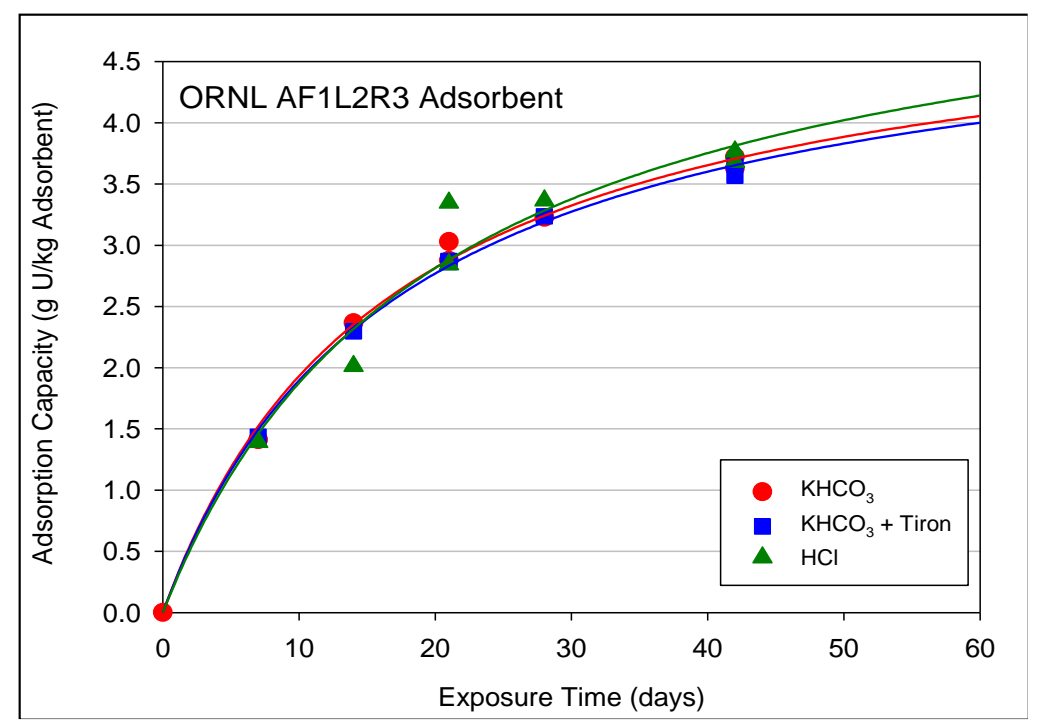

Figure 18. Time-dependent measurements of uranium adsorption capacity of three identical ORNL AF1L2R3 adsorbent braids. Best fit lines drawn through the data points were generated using a one-site ligand saturation model. Note that the 21-day and 42-day time point samples of three braids are all in duplicate.

Table 4. One-site ligand saturation modeling of time-dependent measurements of three identical braids used in recycling study. All data were normalized to a salinity of 35 psu.

\begin{tabular}{ccc}
\hline $\begin{array}{c}\text { Elution } \\
\text { Process }\end{array}$ & $\begin{array}{c}\text { Half-Saturation Time } \\
\text { (days) }\end{array}$ & Saturation Capacity \\
\hline $\mathrm{KHCO}_{3}$ & $16.9 \pm 1.67$ & $5.20 \pm 0.20$ \\
$\mathrm{KHCO}_{3}+\mathrm{Tiron}$ & $17.1 \pm 1.06$ & $5.14 \pm 0.13$ \\
$\mathrm{HCl}$ & $20.0 \pm 5.61$ & $5.63 \pm 0.68$ \\
\hline
\end{tabular}

\subsection{Adsorbent Recycling Experiment - Acid Elution + KOH Reconditioning}

Figure 19 summarizes the time-dependent measurements of uranium adsorption on the ORNL AF1L2R3 braid recycled using $0.5 \mathrm{M} \mathrm{HCl}$ leaching followed by $\mathrm{KOH}$ recondition. Adsorption kinetics were modeled using the one-site ligand saturation modeling. Half-saturation time and saturation capacity information obtained from the one-site ligand saturation modeling of the experimental data are given in Table 5. Uranium adsorption data from the first and the second recycles were all background corrected by subtracting the residual uranium concentration after $0.5 \mathrm{M} \mathrm{HCl} \mathrm{leaching.}$ 


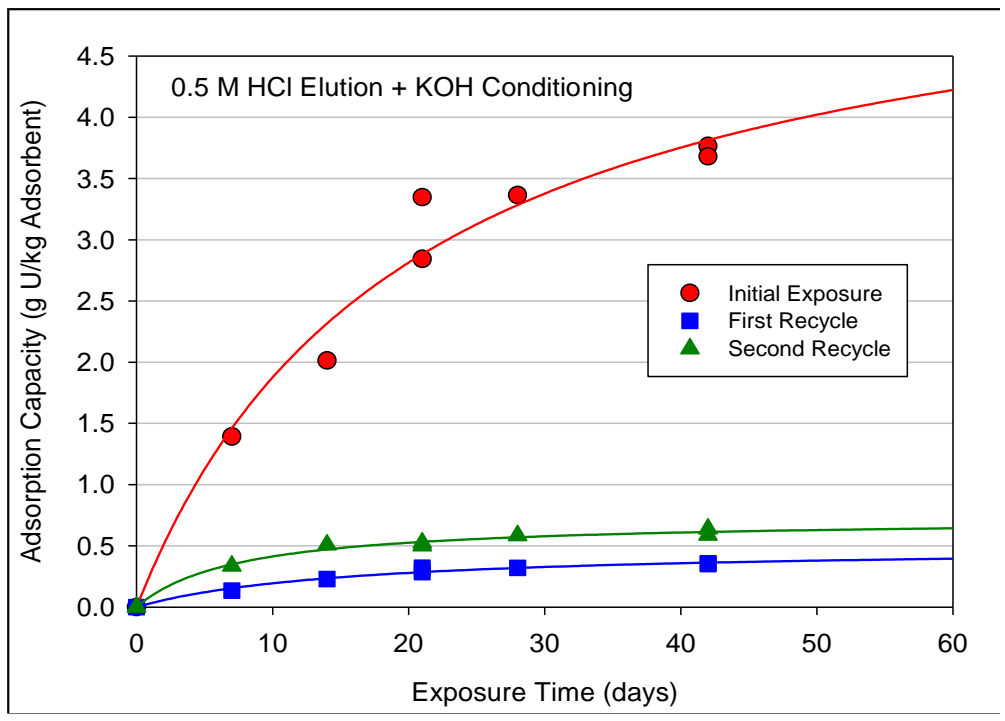

Figure 19. Time-dependent measurements of uranium adsorption capacity with ORNL AF1L2R3 braid recycled using $0.5 \mathrm{M} \mathrm{HCl}$ leaching followed by $\mathrm{KOH}$ reconditioning. Data include the initial seawater exposure and the first and second seawater reexposures after uranium was removed. Lines drawn through the data points were generated with a one-site ligand saturation model. The measured adsorption capacity at each time point for the seawater reexposure (first and second recycles) was background corrected by subtracting the residual uranium concentration after $0.5 \mathrm{M} \mathrm{HCl}$ leaching (Table 5). The 21-day and 42-day data points were done in duplicate. All data were normalized to a salinity of $35 \mathrm{psu}$.

Table 5. One-site ligand saturation modeling of time-dependent measurements of the AF1L2R3 braid recycled by using $0.5 \mathrm{M} \mathrm{HCl}$ leaching followed by $\mathrm{KOH}$ reconditioning. All data were normalized to a salinity of 35 psu.

\begin{tabular}{cccc}
\hline $\begin{array}{c}\text { Seawater } \\
\text { exposure cycle }\end{array}$ & $\begin{array}{c}\text { Residual uranium after } \\
\text { leaching } \\
\text { (g U/ kg adsorbent) }\end{array}$ & $\begin{array}{c}\text { Half-Saturation Time } \\
\text { (days) }\end{array}$ & $\begin{array}{c}\text { Saturation Capacity } \\
\text { (g U/ kg adsorbent) }\end{array}$ \\
\hline Initial & 0.31 & $20.0 \pm 5.6$ & $5.63 \pm 0.68$ \\
First reuse & 0.09 & $15.6 \pm 3.4$ & $0.50 \pm 0.04$ \\
Second reuse & & $7.51 \pm 1.4$ & $0.72 \pm 0.04$ \\
\hline
\end{tabular}

\subsection{Adsorbent Recycling Experiment - $\mathrm{KHCO}_{3}$ Elution}

Figure 20 summarizes the time-dependent measurements of uranium adsorption on the ORNL AF1L2R3 braid recycled using $3 \mathrm{M} \mathrm{KHCO}_{3}$ leaching. Adsorption kinetics were modeled by using the one-site ligand saturation modeling. Half-saturation time and saturation capacity information obtained from the one-site ligand saturation modeling of the experimental data are given in Table 6. Uranium adsorption data for the recycled samples were all background corrected by subtracting the residual uranium concentration after $3 \mathrm{M} \mathrm{KHCO}_{3}$ leaching. 


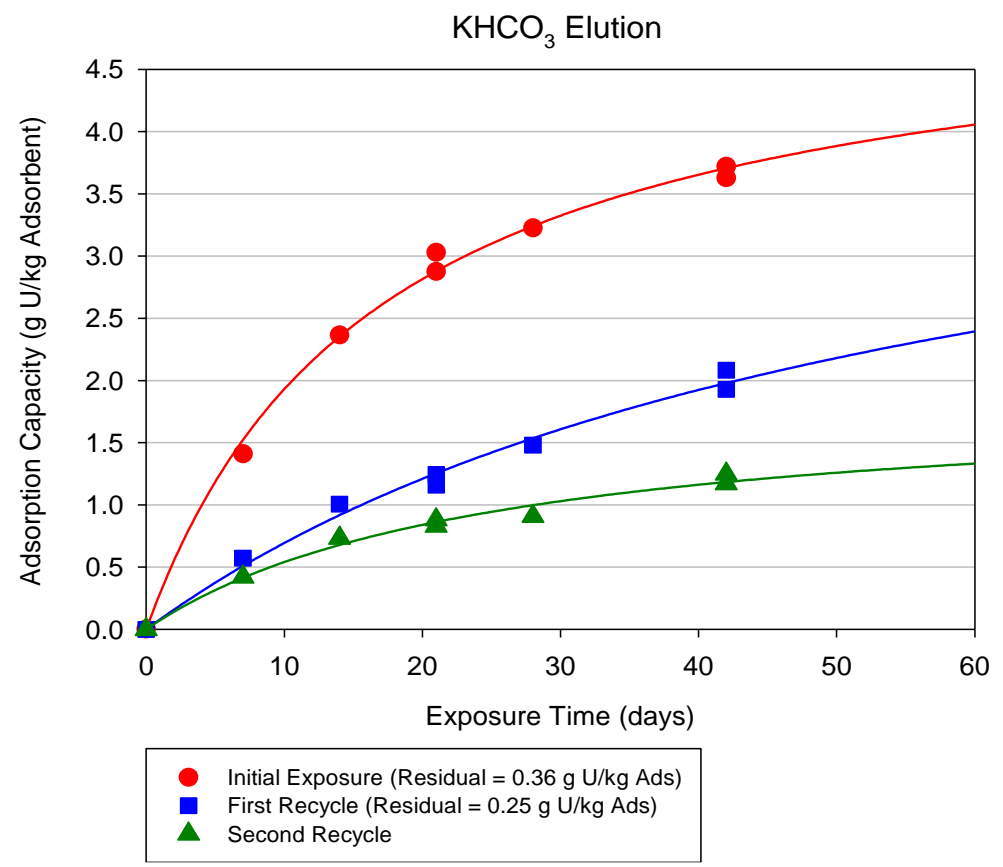

Figure 20. Time-dependent measurements of uranium adsorption capacity with ORNL AF1L2R3 braid recycled by $3 \mathrm{M} \mathrm{KHCO}_{3}$ leaching. Data include the initial seawater exposure and the first and second seawater reexposures after uranium was removed. Lines drawn through the data points were generated with a one-site ligand saturation model. The measured adsorption capacity at each time point from seawater reexposure (first and second recycles) was background corrected by subtracting the residual uranium concentration after $3 \mathrm{M} \mathrm{KHCO}_{3}$ leaching (from Table 6). The 21-day and 42-day data points were done in duplicate. All data were normalized to a salinity of 35 psu.

Table 6. One-site ligand saturation modeling of time-dependent measurements of the AF1L2R3 braid recycled using $3 \mathrm{M} \mathrm{KHCO}_{3}$ leaching. All data were normalized to a salinity of $35 \mathrm{psu}$.

\begin{tabular}{cccc}
\hline $\begin{array}{c}\text { Seawater } \\
\text { exposure cycle }\end{array}$ & $\begin{array}{c}\text { Residual uranium after } \\
\text { leaching } \\
\text { (g U/ kg adsorbent) }\end{array}$ & $\begin{array}{c}\text { Half-Saturation Time } \\
\text { (days) }\end{array}$ & $\begin{array}{c}\text { Saturation Capacity } \\
\text { (g U/ kg adsorbent) }\end{array}$ \\
\hline Initial & 0.36 & $16.9 \pm 1.67$ & $5.20 \pm 0.20$ \\
First reuse & 0.25 & $57.7 \pm 14.6$ & $4.70 \pm 0.78$ \\
Second reuse & & $24.9 \pm 5.19$ & $1.89 \pm 0.19$ \\
\hline
\end{tabular}

\subsection{Adsorbent Recycling Experiment - $\mathrm{KHCO}_{3}$ Elution + Tiron Elution}

Figure 21 summarizes the time-dependent measurements of uranium adsorption on the ORNL AF1L2R3 braid recycled by $3 \mathrm{M} \mathrm{KHCO}_{3}$ leaching followed by $0.5 \mathrm{M}$ Tiron elution. Adsorption kinetics were also modeled using one-site ligand saturation modeling. Details associated with the one-site ligand saturation modeling of the experimental data are given in Table 7. Adsorption data from the two recycles were all background corrected by subtracting the residual uranium concentration after $3 \mathrm{M} \mathrm{KHCO}_{3}$ leaching plus $0.5 \mathrm{M}$ Tiron elution. 


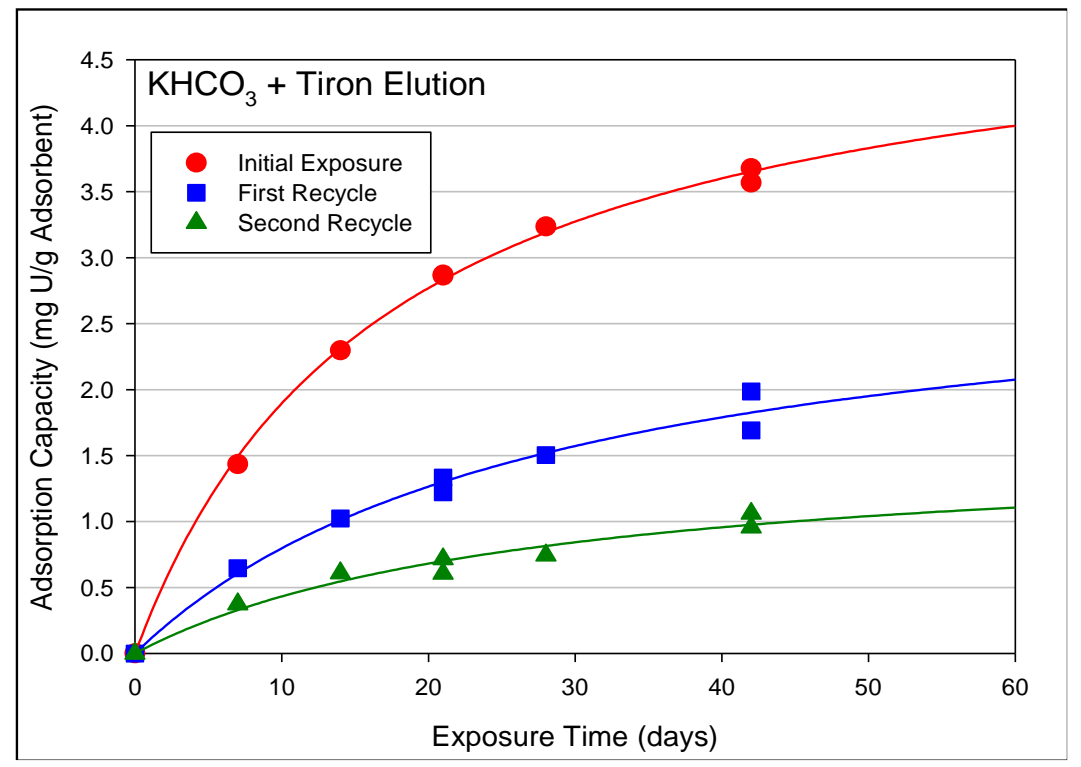

Figure 21. Time-dependent measurements of uranium adsorption capacity with ORNL AF1L2R3 braid recycled by $3 \mathrm{M} \mathrm{KHCO}_{3}$ leaching followed by $0.5 \mathrm{M}$ Tiron elution. Data include the initial seawater exposure and the first and second seawater reexposures after uranium was removed. Lines drawn through the data points were generated with the one-site ligand saturation model. The measured adsorption capacity at each time point from seawater reexposure (first and second cycles) was background corrected by subtracting the residual uranium concentration after $3 \mathrm{M} \mathrm{KHCO}_{3}$ leaching $+0.5 \mathrm{M}$ Tiron elution (from Table 7). Note that the 21-day and 42-day data points were duplicates. All data were normalized to a salinity of 35 psu.

Table 7. One-site ligand saturation modeling of time-dependent measurements of the AF1L2R3 braid recycled by using $3 \mathrm{M} \mathrm{KHCO}_{3}$ leaching followed by $0.5 \mathrm{M}$ Tiron elution. All data were normalized to a salinity of 35 psu.

\begin{tabular}{cccc}
\hline $\begin{array}{c}\text { Seawater } \\
\text { exposure cycle }\end{array}$ & $\begin{array}{c}\text { Residual uranium after } \\
\text { leaching } \\
\text { (g U/ kg adsorbent) }\end{array}$ & $\begin{array}{c}\text { Half-Saturation Time } \\
\text { (days) }\end{array}$ & $\begin{array}{c}\text { Saturation Capacity } \\
\text { (g U/ kg adsorbent) }\end{array}$ \\
\hline Initial & 0.28 & $17.1 \pm 1.06$ & $5.14 \pm 0.13$ \\
First reuse & 0.25 & $28.4 \pm 7.08$ & $3.06 \pm 0.38$ \\
Second reuse & & $27.2 \pm 9.01$ & $1.61 \pm 0.26$ \\
\hline
\end{tabular}

\subsection{Adsorbent Recycling Experiment - Trace Element Removal After Recycling Elution}

The elemental distributions on the adsorbent braids (AF1L2R3) before and after recycling elution, as well as before and after seawater reexposure (original adsorbent vs. reused adsorbent) were further compared to obtain information on (a) trace element removal efficiency by specific leaching method and (b) potential change of elemental distribution on the adsorbent. Figure 22 through Figure 24 show the elemental distributions for different recycling methods (acid leaching, $\mathrm{KHCO}_{3}$ leaching, and $\mathrm{KHCO}_{3}$ leaching + Tiron leaching). 

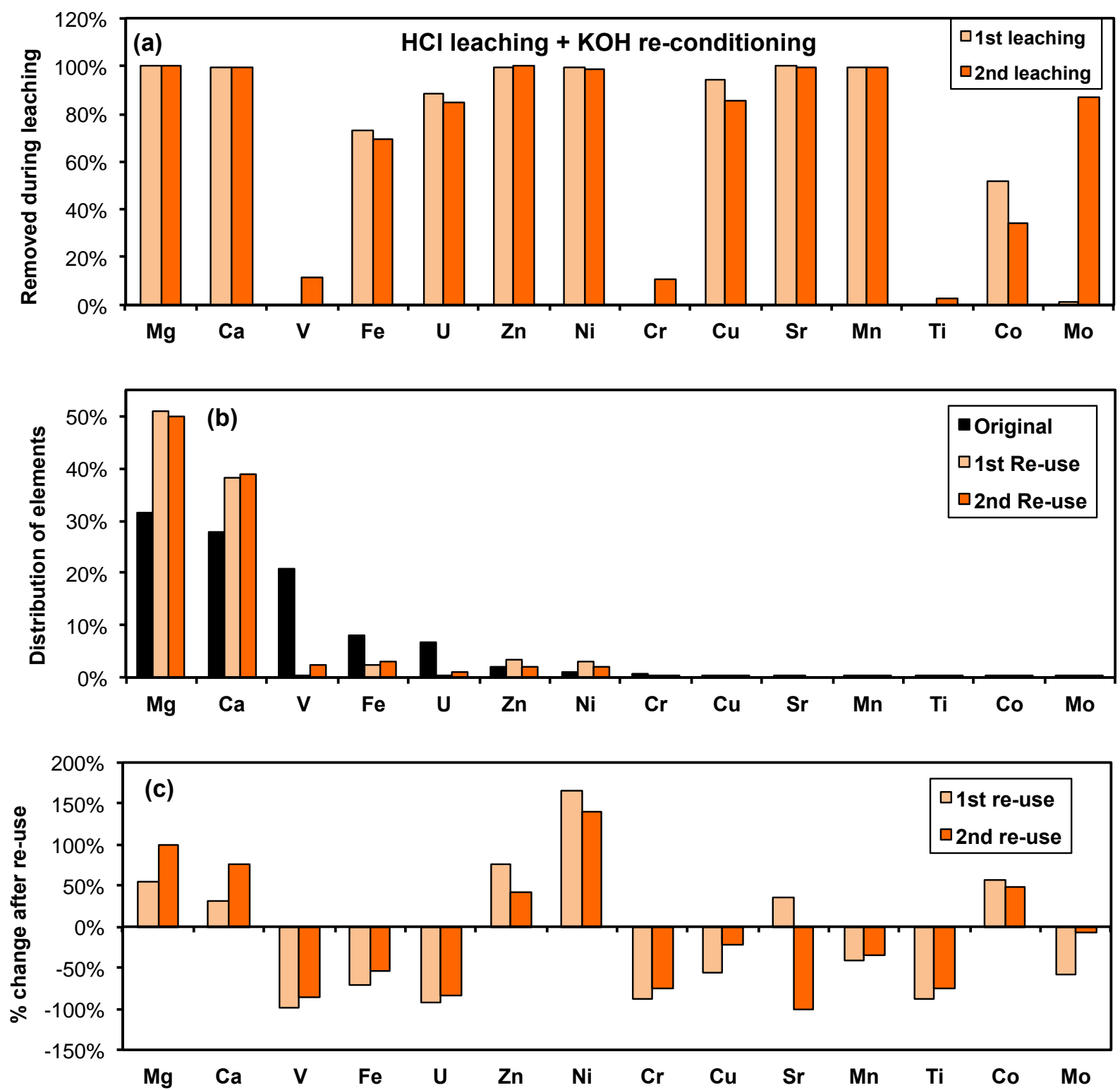

Figure 22. Comparison of trace elements of ORNL AF1L2R3 braid leached by $0.5 \mathrm{M} \mathrm{HCl}+2.5 \% \mathrm{KOH}$ reconditioning for reuse (two reuse cycles): (a) percentage removal of trace element by $0.5 \mathrm{M}$ $\mathrm{HCl}$ leaching; (b) distribution of trace elements adsorbed by braid after 42-day seawater exposure; and (c) percentage change of adsorbed trace element by reused braid relative to those by original braid (before reuse). 

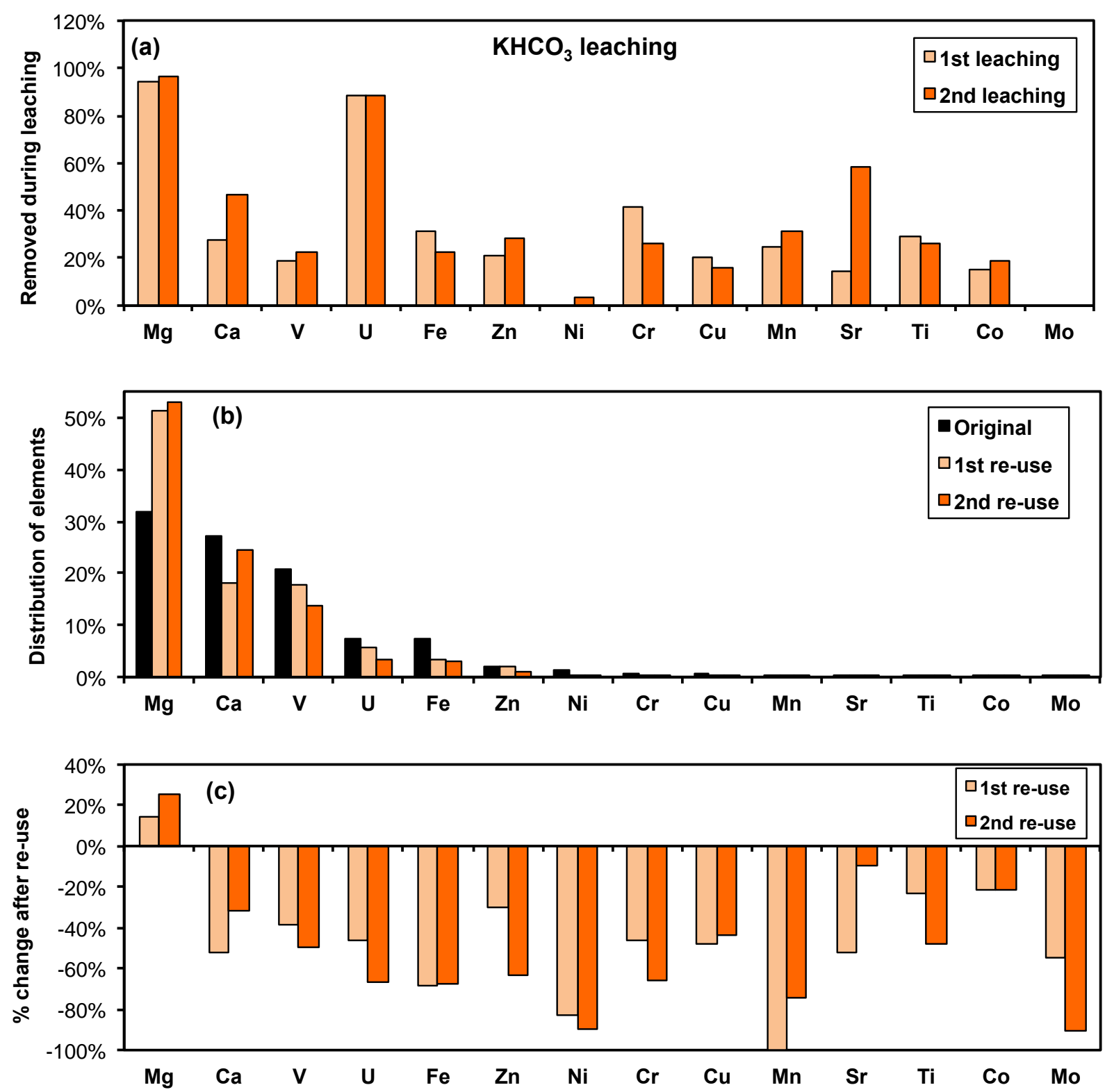

Figure 23. Comparison of trace elements of ORNL AF1L2R3 braid leached by $3 \mathrm{M} \mathrm{KHCO}_{3}$ leaching for reuse (two reuse cycles): (a) percentage removal of trace element by $0.5 \mathrm{M} \mathrm{HCl}$ leaching; (b) distribution of trace elements adsorbed by braid after 42-day seawater exposure; and (c) percentage change of adsorbed trace element by reused braid relative to those by original braid (before reuse). 

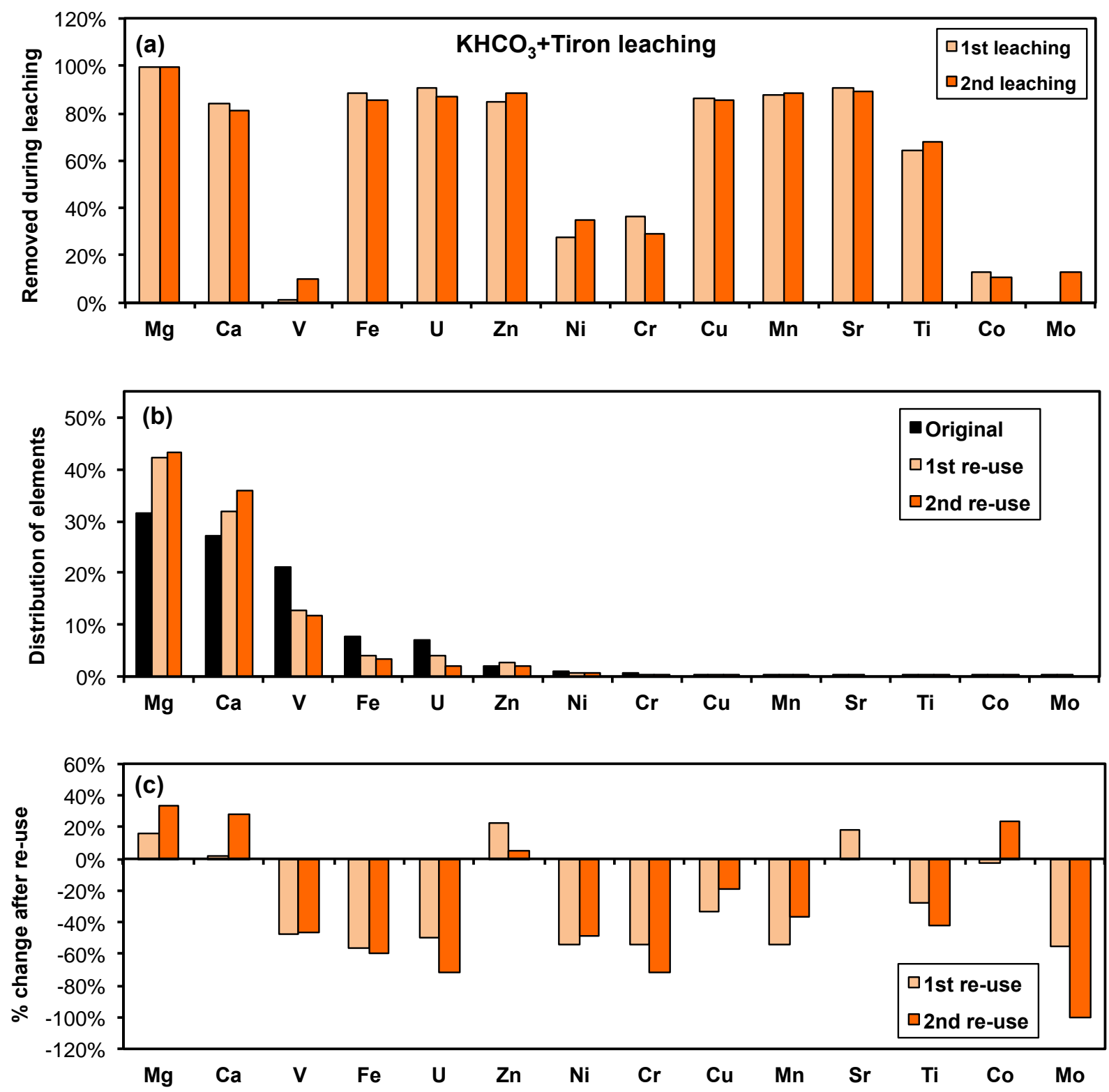

Figure 24. Comparison of trace elements of ORNL AF1L2R3 braid leached by $3 \mathrm{M} \mathrm{KHCO}_{3}$ leaching + $0.5 \mathrm{M}$ Tiron leaching for reuse (two reuse cycles): (a) percentage removal of trace element by $0.5 \mathrm{M} \mathrm{HCl}$ leaching; (b) distribution of trace elements adsorbed by braid after 42-day seawater exposure; and (c) percentage change of adsorbed trace element by reused braid relative to those by original braid (before reuse).

\subsection{Adsorbent Characterization: FTIR}

Figure 25 shows a typical FTIR spectrum of the ORNL AF1 adsorbent after conditioning with $2.5 \%$ $\mathrm{KOH}$ solution at $80^{\circ} \mathrm{C}$ for 1 hour. A broadband in the region of 3000 to $3600 \mathrm{~cm}^{-1}$ is attributed to the stretching vibrations of $-\mathrm{OH}$ (3100 to $3330 \mathrm{~cm}^{-1}$ ) and $-\mathrm{NH}_{2}$ (3400 to $3500 \mathrm{~cm}^{-1}$ ) groups. The two peaks observed at 2918 and $2849 \mathrm{~cm}^{-1}$ are characteristic asymmetrical stretching and symmetrical stretching vibrational bands for $-\mathrm{CH}_{2}-$, respectively. The region between 800 and $2000 \mathrm{~cm}^{-1}$ where absorption of various vibrational modes of amidoxime and carboxylate groups occurs is of interest to this study. Three prominent peaks of interest in this region are the $928 \mathrm{~cm}^{-1}$ band $\left(\mathrm{N}-\mathrm{O}\right.$ stretching), the $1559 \mathrm{~cm}^{-1}$ band 
(- $\mathrm{COO}^{-}$asymmetrical stretching), and the $1643 \mathrm{~cm}^{-1}$ band ( $\mathrm{C}=\mathrm{N}$ stretching). We also considered whether there was an amide II carbonyl stretch in this spectra, which could be a degradation product in the region of the $1559 \mathrm{~cm}^{-1}$ band. We feel the peak at $1643 \mathrm{~cm}^{-1}$ is solely due to a carboxylate anion $\left(-\mathrm{COO}^{-}\right)$ because we observed a reversible conversion between the peak at $1559 \mathrm{~cm}^{-1}$ and a weak shoulder peak at $1706 \mathrm{~cm}^{-1}$ (not visible in this spectra), which we attributed to carboxylic acid peak under basic and acidic conditions. An amide would not show this reversible behavior under acid/base conditions. Figure 26 shows the FTIR spectra of the ORNL AF1 adsorbents in this region by the three different elution methods.

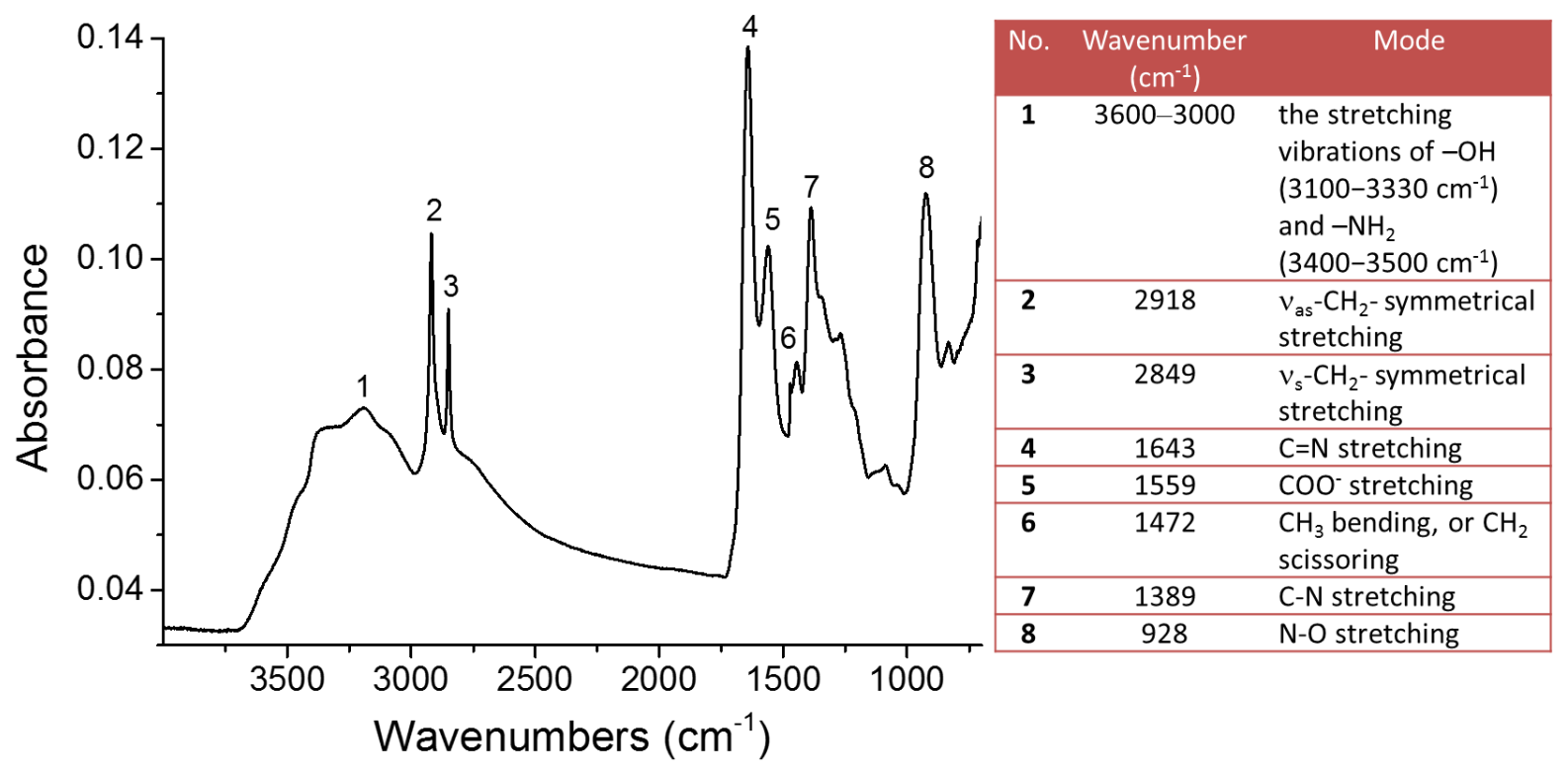

Figure 25. FTIR spectrum of the AF1L2R3 sorbent after conditioning with $2.5 \% \mathrm{KOH}$ solution at $80^{\circ} \mathrm{C}$ for 1 hour.

The peaks in each sample are normalized to the $-\mathrm{CH}_{2}-$ asymmetrical stretching band at $2918 \mathrm{~cm}^{-1}$, which is not affected by the three different elution methods. Table 8 shows variations of the intensity of the $928 \mathrm{~cm}^{-1}$ peak $\left(\mathrm{N}-\mathrm{O}\right.$ stretching) and the relative ratio of the $1643 \mathrm{~cm}-1 / 1559 \mathrm{~cm}^{-1}$ peaks $\left(\mathrm{C}=\mathrm{N} /-\mathrm{COO}^{-}\right.$ stretching) with the three different elution methods. 


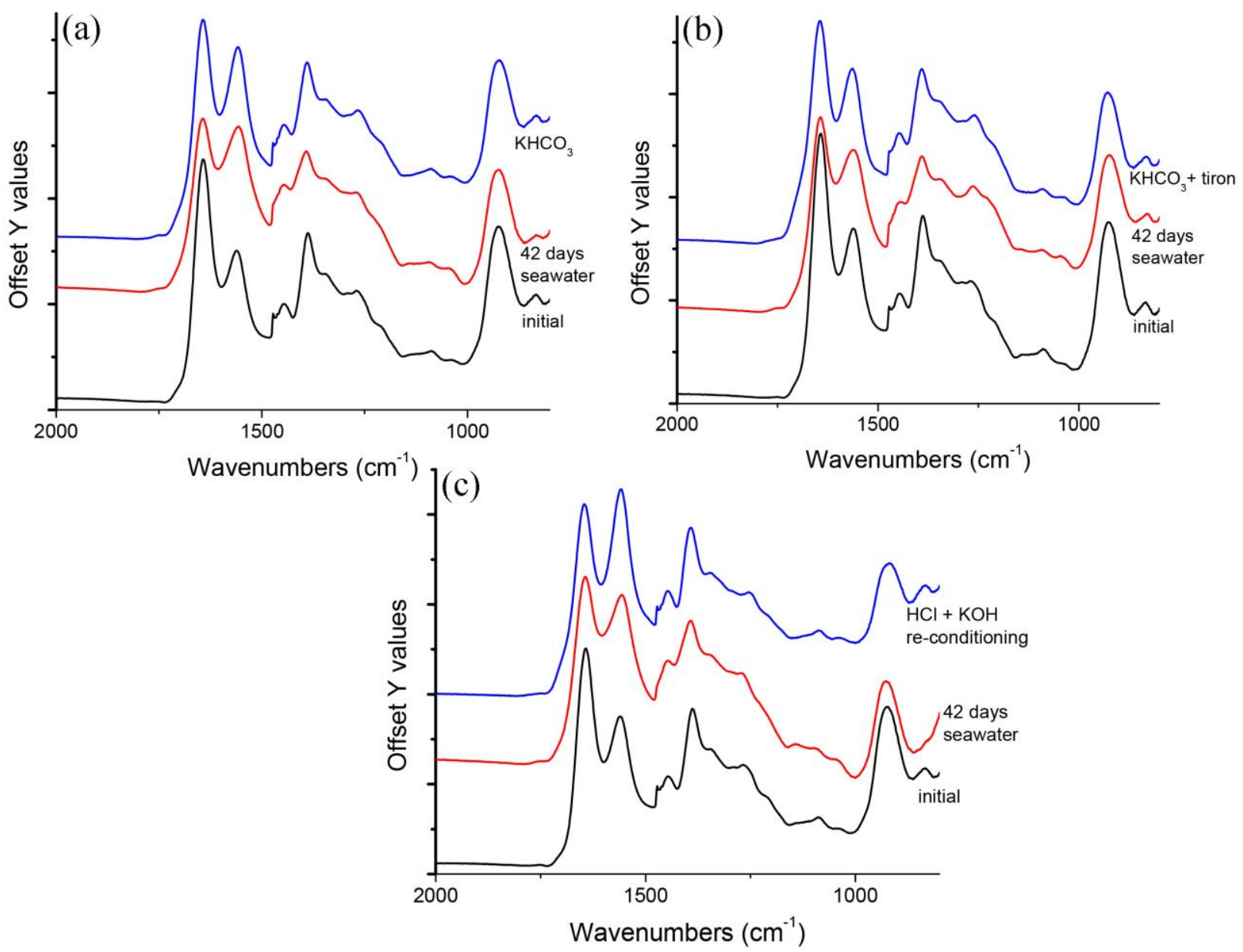

Figure 26. FTIR spectra of the AF1L2R3 braid sorbents by three different elution methods: (a) $\mathrm{KHCO}_{3}$ elution, (b) $\mathrm{KHCO}_{3}+$ Tiron elution, and (c) $\mathrm{HCl}$ elution $+\mathrm{KOH}$ reconditioning in the region 800 to $2000 \mathrm{~cm}^{-1}$. The spectra are normalized to the $-\mathrm{CH}_{2}-$ asymmetrical stretching peak at $2918 \mathrm{~cm}^{-1}$.

Table 8. Peak intensity of $\mathrm{N}-\mathrm{O}$ stretching $\left(928 \mathrm{~cm}^{-1}\right)$ and ratio of $\mathrm{C}=\mathrm{N} /-\mathrm{COO}^{-}$stretching $\left(\mathrm{I}_{1643} / \mathrm{I}_{1559}\right)$ of the AF1L2R3 braid sorbents under three different elution methods. The peak intensities are normalized to $-\mathrm{CH}_{2}-$ asymmetrical stretching peak at $2918 \mathrm{~cm}^{-1}$.

\begin{tabular}{|c|c|c|}
\hline Description & $\begin{array}{l}\text { IR peak ratio } \\
\text { of } \mathrm{I}_{1643} / \mathrm{I}_{1559}\end{array}$ & IR peak intensity of $\mathrm{I}_{928}$ \\
\hline AF1L2R3 braid-1 initial & 1.36 & 0.51 \\
\hline 42 days seawater exposure & 1.03 & 0.43 \\
\hline After $\mathrm{KHCO}_{3}$ leaching & 1.09 & 0.45 \\
\hline AF1L2R3 braid-2 initial & 1.36 & 0.57 \\
\hline 42 days seawater exposure & 1.12 & 0.43 \\
\hline After $\mathrm{KHCO}_{3}+$ Tiron leaching & 1.18 & 0.43 \\
\hline AF1L2R3 braid-3 initial & 1.29 & 0.55 \\
\hline 42 days seawater exposure & 1.07 & 0.43 \\
\hline After $\mathrm{HCl}$ and $\mathrm{KOH}$ reconditioning & 0.94 & 0.34 \\
\hline
\end{tabular}




\subsection{Adsorbent Characterization: SEM}

Figure 27 shows a typical SEM image of the ORNL high-surface-area polymeric adsorbent after RIGP grafting and before $\mathrm{KOH}$ conditioning. This unique fin-like or gear-shaped structure provides the high surface area of the adsorbent. After grafting and immediately prior to seawater exposure, the adsorbents are treated with $2.5 \% \mathrm{KOH}$ at $80^{\circ} \mathrm{C}$ for 1 to 3 hours to make the material hydrophilic. Without this $\mathrm{KOH}$ conditioning process, the adsorbent has near zero uranium adsorption capacity in marine testing. However, the $\mathrm{KOH}$ conditioning can also cause physical damage to the sorbent material. Figure 28 shows an SEM image of the sorbent after $2.5 \% \mathrm{KOH}$ conditioning at $80^{\circ} \mathrm{C}$ for 1 hour. Some physical damage to the surface of the sorbent is apparent.

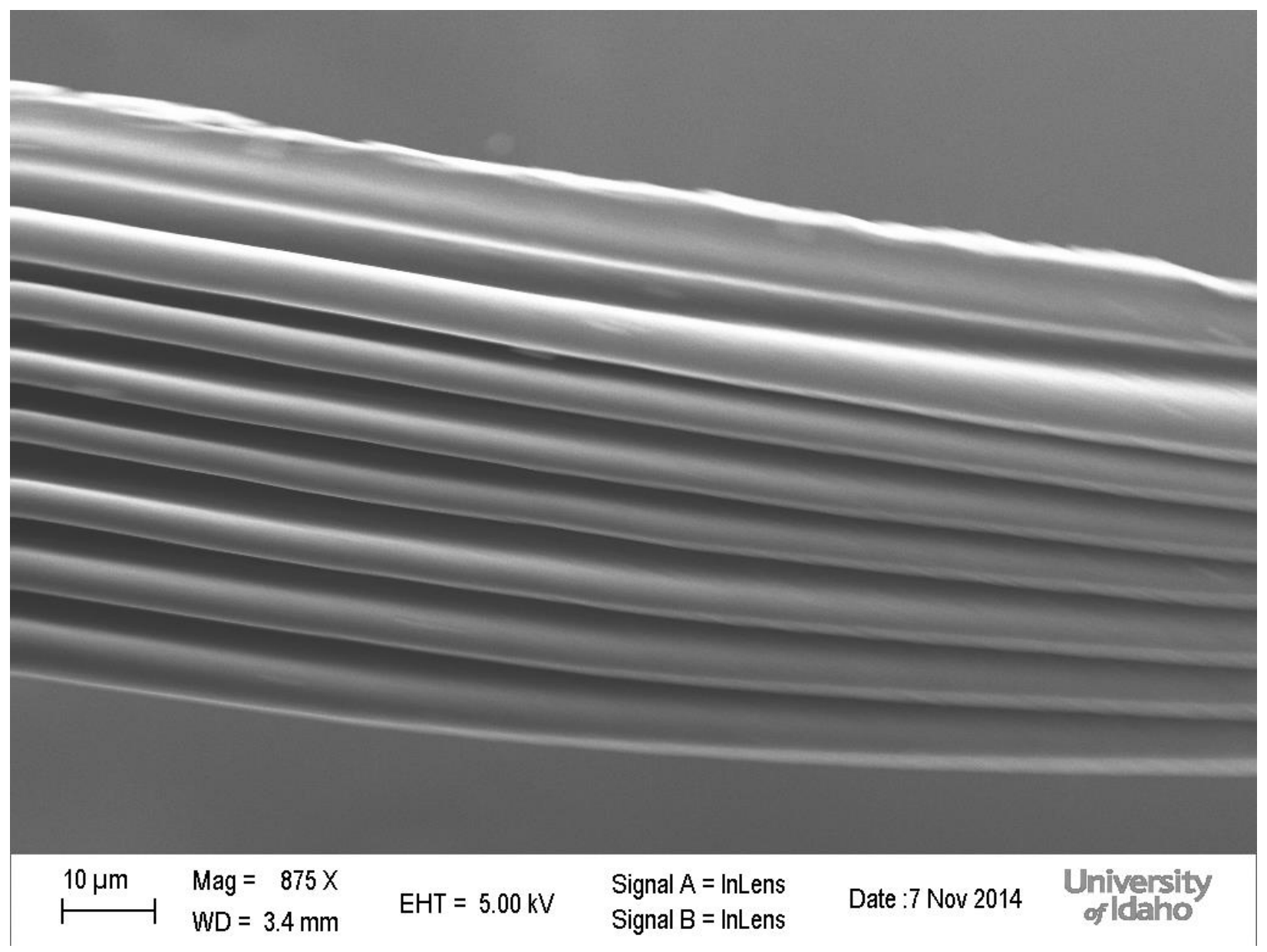

Figure 27. SEM image of the amidoxime grafted high-surface-area polyethylene AF1L2R3 fiber obtained from ORNL prior to $\mathrm{KOH}$ conditioning. 


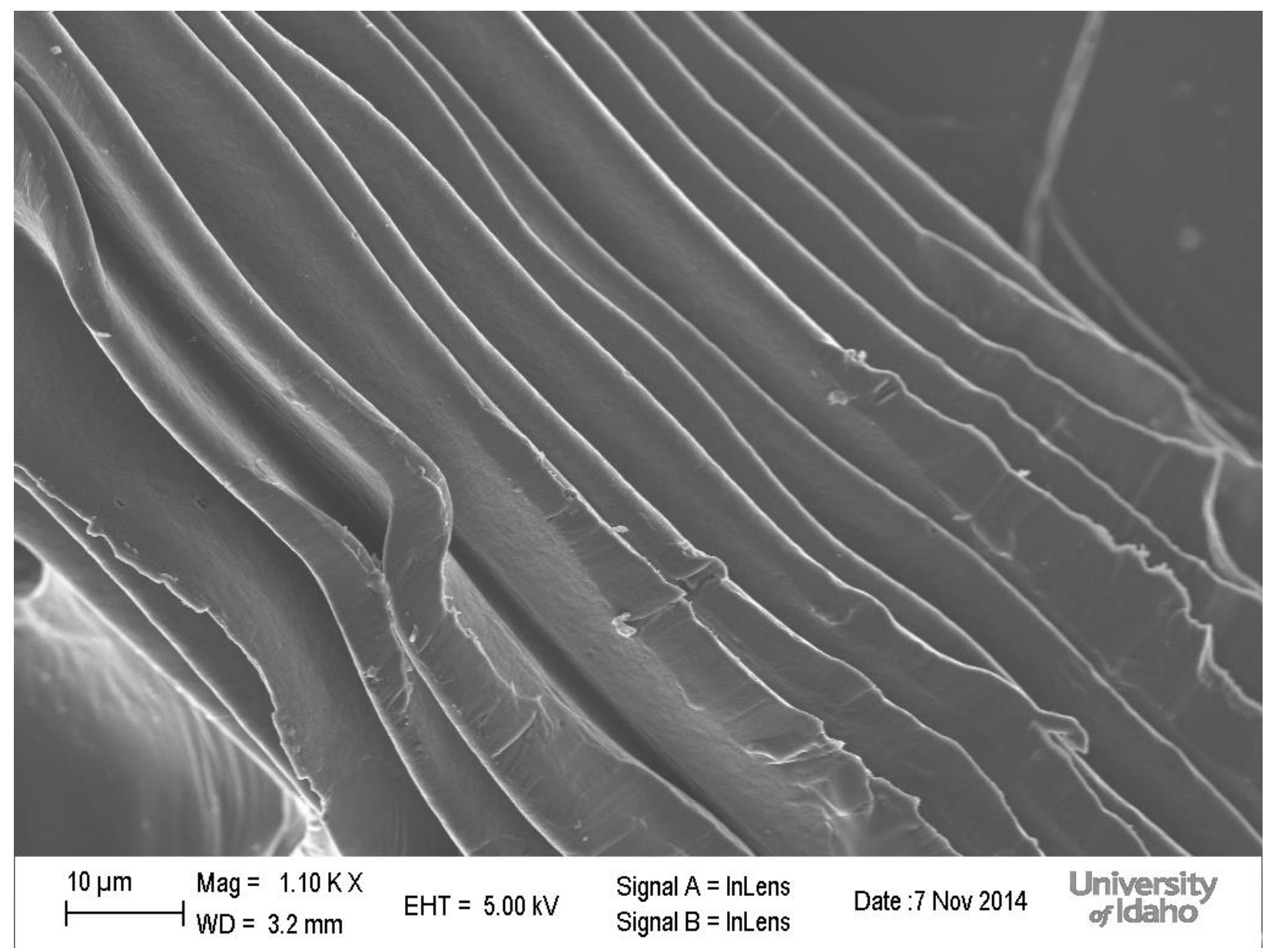

Figure 28. SEM image of the high-surface-area polyethylene AF1L2R3 fibers after 1 hour of KOH conditioning at $80^{\circ} \mathrm{C}$.

After $\mathrm{KOH}$ conditioning $\left(2.5 \% \mathrm{KOH} 1\right.$ hour at $\left.80^{\circ} \mathrm{C}\right)$ and subsequent exposure to seawater for 42 days, more physical damage appears to develop (Figure 29). We can see some breakdown of the surface of the adsorbent fiber. Finally, Figure 30 shows an SEM image of the ORNL AF1 adsorbent after $\mathrm{KOH}$ conditioning $\left(2.5 \% \mathrm{KOH}\right.$ for 1 hour at $\left.80^{\circ} \mathrm{C}\right)$, exposure to seawater for 42 days, $0.5 \mathrm{M} \mathrm{HCl}$ elution to strip off the uranium, and a necessary $\mathrm{KOH}$ reconditioning step to ready the adsorbent for additional seawater exposure (i.e., reuse). There is clear evidence of fractures in the adsorbent fiber. In addition, the "fins" appear to be collapsed and sticking together. There is the possibility that the physical changes observed are related to swelling /drying effects from preparation of the samples for SEM. Repeating these observations with an environmental SEM will help to clarify whether sample preparation is altering the SEM scans. 


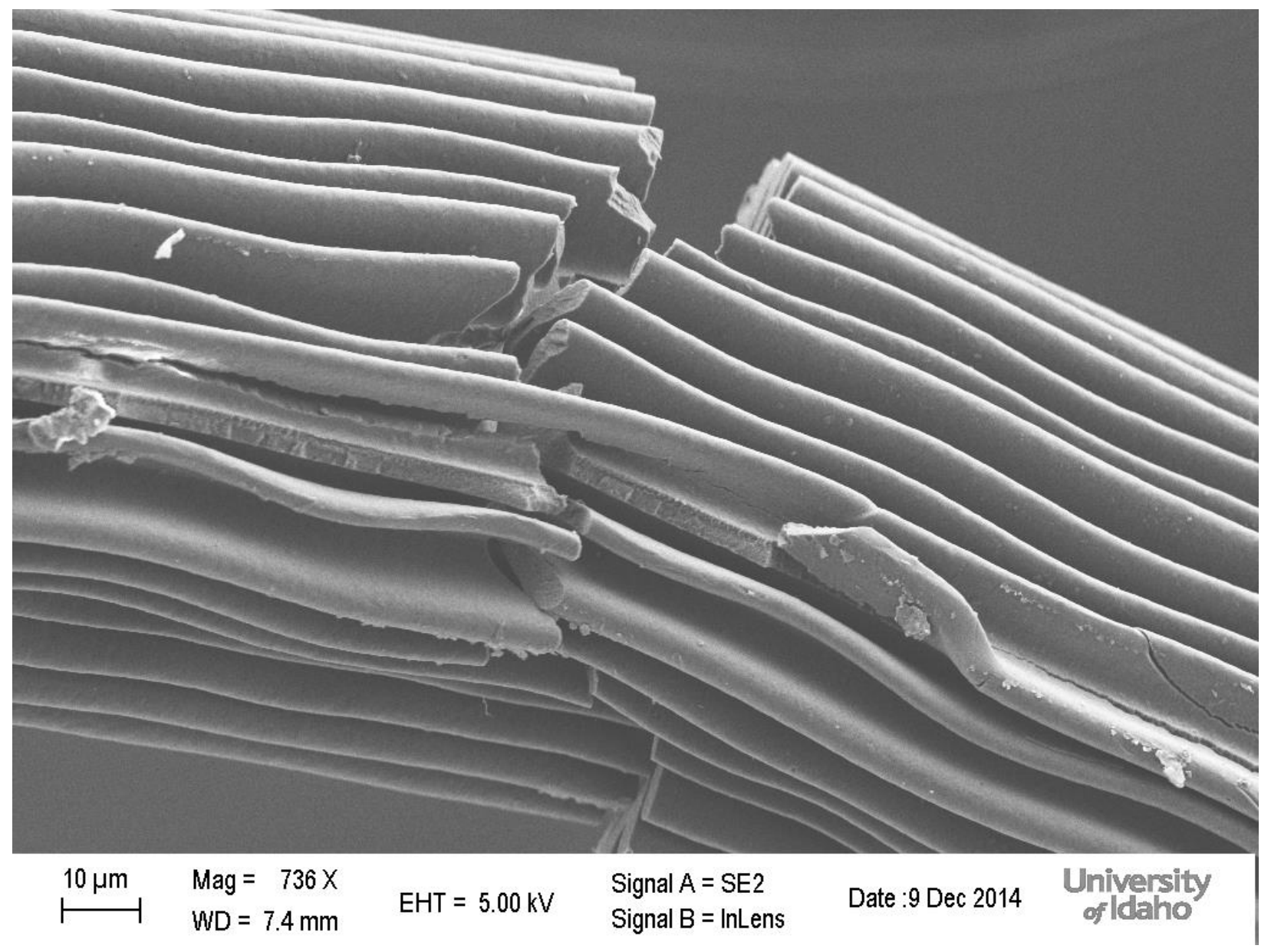

Figure 29. SEM image of the $\mathrm{KOH}$ treated AF1L2R3 sorbent after 42 days seawater exposure. 


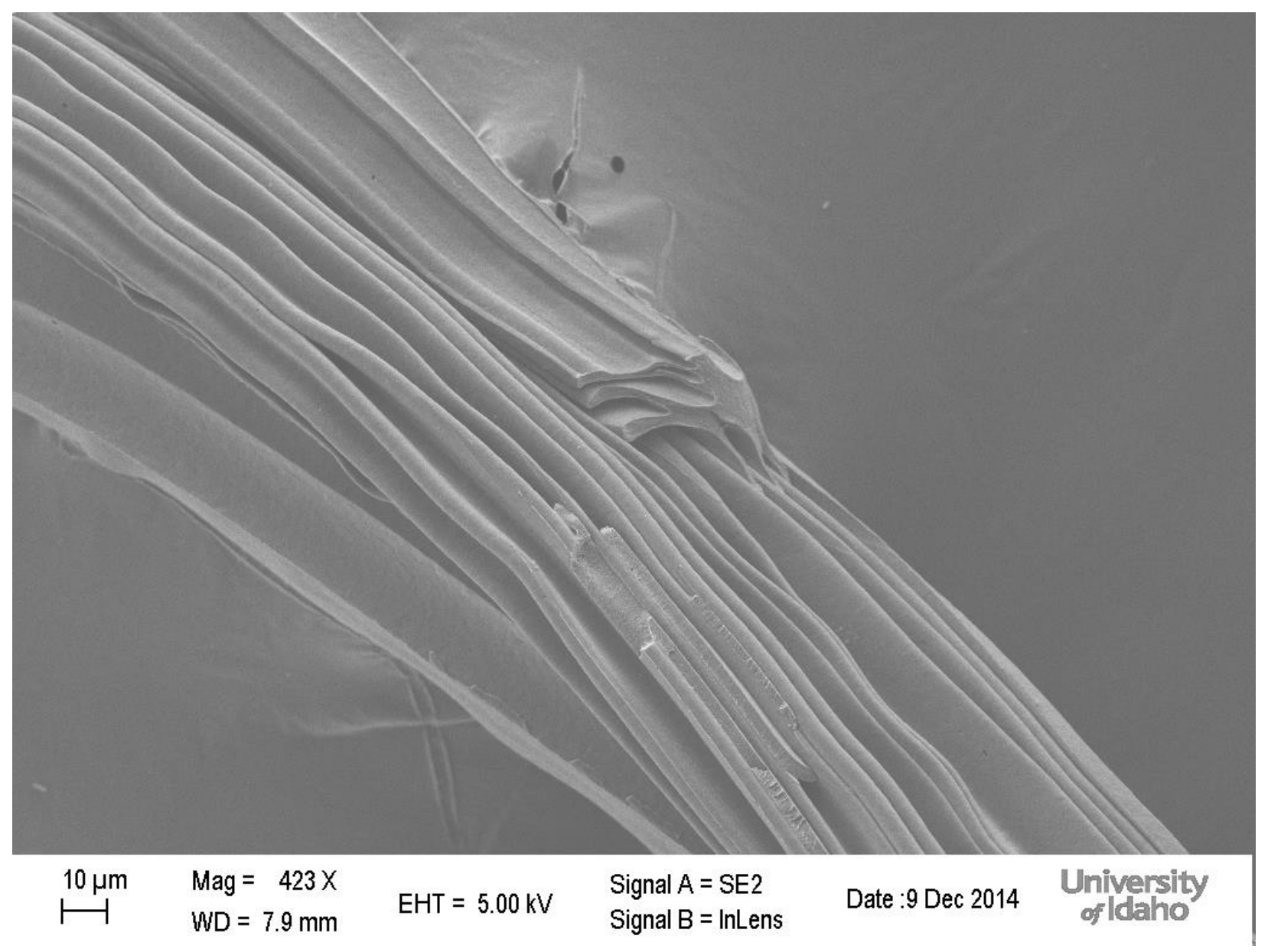

Figure 30. SEM image of the AF1L2R3 sorbent after $\mathrm{HCl}$ elution and $\mathrm{KOH}$ reconditioning.

\subsection{Discussion}

\subsection{Comparison Elution Approaches for Adsorbent Reuse}

The near-identical uranium adsorption kinetics and capacity of the three AF1L2R3 braids observed after 42 days of seawater exposure (Figure 18 and Table 4) indicate that these braids performed identically in terms of adsorption capacity and adsorption kinetics, and thus are an excellent batch of test materials for comparison of the different recycling approaches. The adsorption performance of these three AF1L2R3 adsorbents is also similar to other, previously tested AF1 formulations, which have a saturation capacity of $\sim 5$ to $6 \mathrm{~g} \mathrm{U} / \mathrm{kg}$ adsorbent and a half-saturation time of $\sim 20$ to 30 days. This is clear evidence that the procedures used for preparation of the adsorbent braids are robust and consistently produce materials with identical performance properties.

All three elution schemes removed $88 \%$ to $90 \%$ of the uranium sequestered by the adsorbent after 42 days of exposure in natural seawater (see Figure 22 to Figure 24 and Table 9). However, the elution schemes did a poor job of removing V (0\% to $23 \%)$. The Tiron elution scheme removed slightly more $\mathrm{Fe}$ from the adsorbent ( $85 \%$ to $88 \%$ ) compared to acid leaching (69\% to $73 \%$ ). Very little Fe was removed with $\mathrm{KHCO}_{3}$ elution alone $(22 \%$ to $32 \%)$. Acid leaching $(0.5 \mathrm{M} \mathrm{HCl})$ in general can remove a significant portion of many trace elements, with the exception of $\mathrm{V}, \mathrm{Cr}$, and $\mathrm{Ti} . \mathrm{KHCO}_{3}$ leaching is a more uraniumselective leaching method. $\mathrm{KHCO}_{3}$ leaching is only effective at removing $\mathrm{U}$ and $\mathrm{Mg}$ (>85\%, Figure 23). 
The lower uranium elution efficiency observed with leaching braids, compared to the leaching efficiency confirmation tests using fibers (compare Figure 15 and Figure 16 with Figure 22 through Figure 24) suggests that some portions of the braids may not be fully in good contact with the leaching solutions.

Table 9. Percentage removal of U, Fe, and V from AF1L2R3 braids after being leached by three different methods. The percentage changes were calculated relative to the adsorption data of adsorbent before being reused.

\begin{tabular}{|c|c|c|c|c|c|c|c|c|c|}
\hline \multirow{2}{*}{$\begin{array}{c}\text { Seawater } \\
\text { Exposure Cycle }\end{array}$} & \multicolumn{3}{|c|}{$\begin{array}{c}0.5 \mathrm{M} \mathrm{HCl}+\mathrm{KOH} \\
\text { Reconditioning }\end{array}$} & \multicolumn{3}{|c|}{$3 \mathrm{M} \mathrm{KHCO}_{3}$} & \multicolumn{3}{|c|}{$3 \mathrm{M} \mathrm{KHCO}_{3}+$ Tiron } \\
\hline & $\bar{U}$ & $\mathrm{Fe}$ & $\mathrm{V}$ & $\mathrm{U}$ & $\mathrm{Fe}$ & $\mathrm{V}$ & $\bar{U}$ & $\mathrm{Fe}$ & $\mathrm{V}$ \\
\hline First leaching & $88 \%$ & $73 \%$ & $0 \%$ & $88 \%$ & $32 \%$ & $19 \%$ & $90 \%$ & $88 \%$ & $1.0 \%$ \\
\hline Second leaching & $85 \%$ & $69 \%$ & $11 \%$ & $88 \%$ & $22 \%$ & $23 \%$ & $87 \%$ & $85 \%$ & $10 \%$ \\
\hline
\end{tabular}

The ability of the adsorbent to recover $U$ following an elution cycle is summarized in Table 10 . There was a substantial reduction $(>80 \%)$ in the $\mathrm{U}$ adsorption capacity in subsequent adsorbent reuse following $0.5 \mathrm{M} \mathrm{HCl}$ acid elution and $\mathrm{KOH}$ reconditioning. The specific reason for this large reduction in capacity is currently unknown, but it suggests that the combination of acid elution and $\mathrm{KOH}$ reconditioning causes physical and/or chemical damage to the adsorbent. Results of adsorbent characterization using FTIR and SEM presented in the next section support the contention of chemical/physical damage to the adsorbent. Pan et al. (2014) have reported that acid elution can deteriorate the adsorbent due to acid hydrolysis of amidoxime groups. Moreover, we have recently observed that prolonged $\mathrm{KOH}$ treatment under high temperature (e.g., $80^{\circ} \mathrm{C}$ ) can cause degradation of amidoxime groups and damage to the physical structure of the adsorbent (Pan et al., 2015).

Table 10. Percentage recovery in uranium adsorption capacity of the ORNL AF1L2R3 braided adsorbent after being recycled by three different elution methods. Shown are the relative change in adsorption capacity following an elution scheme and a subsequent 42-day seawater exposure and the modeled saturation capacity. The percentage change was determined relative to the adsorption capacity obtained on the initial seawater exposure.

\begin{tabular}{|c|c|c|c|c|c|c|}
\hline \multirow{2}{*}{$\begin{array}{c}\text { Seawater } \\
\text { Exposure Cycle }\end{array}$} & \multicolumn{2}{|c|}{$\begin{array}{c}0.5 \mathrm{M} \mathrm{HCl}+\mathrm{KOH} \\
\text { Reconditioning }\end{array}$} & \multicolumn{2}{|c|}{$3 \mathrm{M} \mathrm{KHCO}_{3}$} & \multicolumn{2}{|c|}{$3 \mathrm{M} \mathrm{KHCO}_{3}+$ Tiron } \\
\hline & 42 days & Saturation & 42 days & Saturation & 42 days & Saturation \\
\hline First reuse & $7 \%$ & $9 \%$ & $54 \%$ & $90 \%$ & $50 \%$ & $60 \%$ \\
\hline Second reuse & $16 \%$ & $13 \%$ & $33 \%$ & $36 \%$ & $28 \%$ & $31 \%$ \\
\hline
\end{tabular}

Adsorbent reuse following $3 \mathrm{M} \mathrm{KHCO}_{3}$ elution results in a higher $\mathrm{U}$ adsorption capacity (33\% to $54 \%$ of the original capacity) compared to acid elution and reconditioning (Table 10). Including Tiron elution after $\mathrm{KHCO}_{3}$ elution does not appear to significantly improve $\mathrm{U}$ recovery during adsorbent reuse, despite the fact that Tiron can remove a significant amount (>85\%) of the adsorbed Fe (Table 9). While this test with Fe is limited in scope, it suggests that removing other metal ions that compete with $\mathrm{U}$ for binding sites on the adsorbent may not be beneficial to the overall performance of the adsorbent during reuse.

Interestingly, performing elution recycling tests with simulated seawater in a laboratory resulted in $100 \%$ recovery of adsorbent capacity through several recycling events using elution with $3 \mathrm{M} \mathrm{KHCO}_{3}$ or $3 \mathrm{M} \mathrm{KHCO}_{3}$ followed by $0.5 \mathrm{M}$ Tiron ${ }^{1}$. Clearly, simulated seawater is not necessarily a good proxy for

\footnotetext{
${ }^{1}$ Pan, HB and C Chien, personal communication, 2015. Data not presented.
} 
real seawater tests involving amidoxime-based adsorbents. The reason for the discrepancy is not clear, but it could involve a number of factors, including use of elevated uranium concentrations in simulated tests; absence of key metal binding ligands in simulated tests; shorter duration simulated tests (hours to days) compared to natural seawater tests (several weeks); absence of natural organic matter in simulated tests that is present in natural seawater; and the presence of live biological organisms (especially microbial organisms) in natural seawater tests that would be absent in simulated seawater tests.

A major advantage of the $\mathrm{KHCO}_{3}$ elution approach over acid elution is that it doesn't require a $\mathrm{KOH}$ reconditioning step prior to adsorbent reuse. As described previously, $\mathrm{KOH}$ conditioning can cause physical and chemical damage to the adsorbent (see Figure 28 and Pan et al., 2015). A similar change in the physical structure of the adsorbent was not observed with $\mathrm{KHCO}_{3}$ elution (see next section).

\subsection{Effects of Seawater Exposure and Elution Recycling Approaches on the Physical and Chemical Properties of Amidoxime-Based Polymeric Adsorbents}

FTIR measurements show that conversion of amidoxime groups to carboxylate groups occured to all three AF1L2R3 braided adsorbents used in the elution study during 42 days of seawater exposure. This determination is based on the decrease in absorbance of the $\mathrm{N}-\mathrm{O}$ stretching $\left(928 \mathrm{~cm}^{-1}\right)$ and in the ratio of $\mathrm{C}=\mathrm{N} /-\mathrm{COO}^{-}$stretching $\left(\mathrm{I}_{1643} / \mathrm{I}_{1559}\right)$ shown in Table 8 . There is about a $20 \%$ decrease in the amidoxime groups (based on the decrease in the intensity of the $-\mathrm{NO}$ stretching peak $\mathrm{I}_{928}$ ) for all three adsorbents after 42 days in seawater exposure. It is unclear if this conversion is due to a biotic or an abiotic process.

About a $20 \%$ decrease in amidoxime groups was observed after $\mathrm{HCl}$ elution and $\mathrm{KOH}$ reconditioning based on the decrease in the intensity of the -NO stretching peak $\mathrm{I}_{928}$ (Table 8). Both the 1643 and 928 peak intensities decrease after $\mathrm{HCl}$ elution, followed by $\mathrm{KOH}$ reconditioning, but their intensity ratio (1643/928) remains the same. The 1643/928 ratios of initial and $\mathrm{HCl}$ elution followed by $\mathrm{KOH}$ reconditioning are 1.24 and 1.28 , respectively.

Conversion of single amidoxime molecules to carboxylic acid molecules in highly acidic or alkaline solutions has been reported by Hay and co-workers (Kang et al., 2012). The conversion would lower amidoxime group density in the sorbent, which could lead to a reduction in uranium adsorption capacity. Physical damage to the adsorbent structure after $\mathrm{HCl}$ elution and $\mathrm{KOH}$ reconditioning was also observed from SEM images (Figure 30). How and whether this physical damage relates to a reduction in U adsorption capacity is not clear. Our recent study (Pan et al., 2015) on the effect of KOH conditioning on ORNL high-surface-area fiber adsorbent has revealed that $\mathrm{KOH}$ conditioning can adversely affect uranium adsorption capacity if the conditioning duration and or temperature are too high.

There was no change in ratio of $\mathrm{C}=\mathrm{N} /-\mathrm{COO}^{-}$stretching $\left(\mathrm{I}_{1643} / \mathrm{I}_{1559}\right)$ or in the intensity of the $-\mathrm{NO}$ stretching peak $\mathrm{I}_{28}$ of the AF1L2R3 braid sorbent after either the $\mathrm{KHCO}_{3}$ elution or the $\mathrm{KHCO}_{3}+$ Tiron elution. Moreover, physical damage to the sorbent structure after the $\mathrm{KHCO}_{3}$ elution process was not observed in the SEM images. These observations suggest that $\mathrm{KHCO}_{3}$ and Tiron elution have minimal impact on the physical and chemical integrity of amidoxime-based polymeric adsorbents compared to that observed with the $0.5 \mathrm{M} \mathrm{HCl}$ elution followed by $\mathrm{KOH}$ reconditioning for adsorbent reuse. 


\subsection{Adsorption Kinetics}

The uranium adsorption rate after the first recycle is generally slower than that observed for the original use of the adsorbent, with the exception of the acid elution treatment (Table 5 to Table 7). This is especially evident in the $\mathrm{KHCO}_{3}$ leached braid, with a half saturation time of 58 days on the first reuse compared to 17 days initially (Table 6). Interestingly, modeled saturation capacities are similar (5.20 \pm $0.20 \mathrm{vs} .4 .70 \pm 0.78 \mathrm{~g} \mathrm{U} / \mathrm{kg}$ adsorbent for the original braid and first reused braid, respectively). The slow uranium sorption kinetics in the reused adsorbent may imply that there are newly introduced interferences during long-term seawater exposure that slow down the uranium uptake to the adsorbent.

Potential interferences that can slow down uranium adsorption rate in real seawater are adsorption of dissolved organic matter (DOM) on the sorbent surface and/or biofouling. Since our adsorption experiments were conducted with $0.45 \mu \mathrm{m}$ filtered seawater in an opaque black flume, biofouling is probably limited. However, the DOM sorption in the real seawater system is an inevitable process because DOM is ubiquitous in the natural waters and it can't be removed by $0.45 \mu \mathrm{m}$ filtration. If DOM absorption is occurring, it may eventually impact the adsorbents' uranium adsorption capacity permanently with repeated seawater exposures (multiple reuse cycles).

\subsection{Effect of DOM Removal from Seawater-Exposed Adsorbents on U Adsorption Capacity}

Oceanic DOM, like terrestrial DOM, is a heterogeneous mixture of organic molecules with molecular weight spanning from <1000 Da to >1000 Da. Primary biochemical components of oceanic DOM include proteins, lipids, carbohydrates, and abundant uncharacterized fractions (Benner, 2002; Ogawa and Tanoue, 2003; Hansell, 2013; Tanaka et al., 2014). Humic substances, which are the mixtures of degradation products of organic matter, represent a significant portion in the molecularly uncharacterized DOM components and can be dissolved in an alkaline solution such as $\mathrm{NaOH}$. We hypothesized that, if DOM adsorption played a role in hindering the uranium adsorption on the adsorbents, removal of humic substances from the adsorbent by using an additional $\mathrm{NaOH}$ rinse may mitigate the impact of DOM adsorption.

We conducted a simple exploratory test to evaluate the potential interference from DOM adsorption on $U$ adsorption capacity during adsorbent reuse. Some fibers were snipped from the ORNL AF1L2R3 braided adsorbent that had undergone 42 days of seawater exposure and was eluted with $\mathrm{KHCO}_{3}$ and reused once (first reuse). The fibers were rinsed with $0.5 \mathrm{M} \mathrm{NaOH}$ for 1.5 hours at room temperature to remove adsorbed DOM. The $\mathrm{NaOH}$-treated fibers were then packed into two PNNL flow-through columns and installed on the seawater exposure system for a 42-day exposure.

Figure 31 compares the $\mathrm{U}$ adsorption capacity obtained from this exploratory test with the second reuse results obtained from the $\mathrm{KHCO}_{3}$ elution/recycling experiment. The fibers treated with $\mathrm{NaOH}$ had a higher $\mathrm{U}$ adsorption capacity (33\% higher) than those that received no $\mathrm{NaOH}$ treatment. This test provides preliminary evidence that adsorption of DOM from seawater onto the adsorbent material during extended exposure may be influencing $U$ adsorption capacity. Moreover, it suggests that developing an elution protocol that also removes adsorbed DOM prior to adsorbent reuse may improve adsorbent performance. 


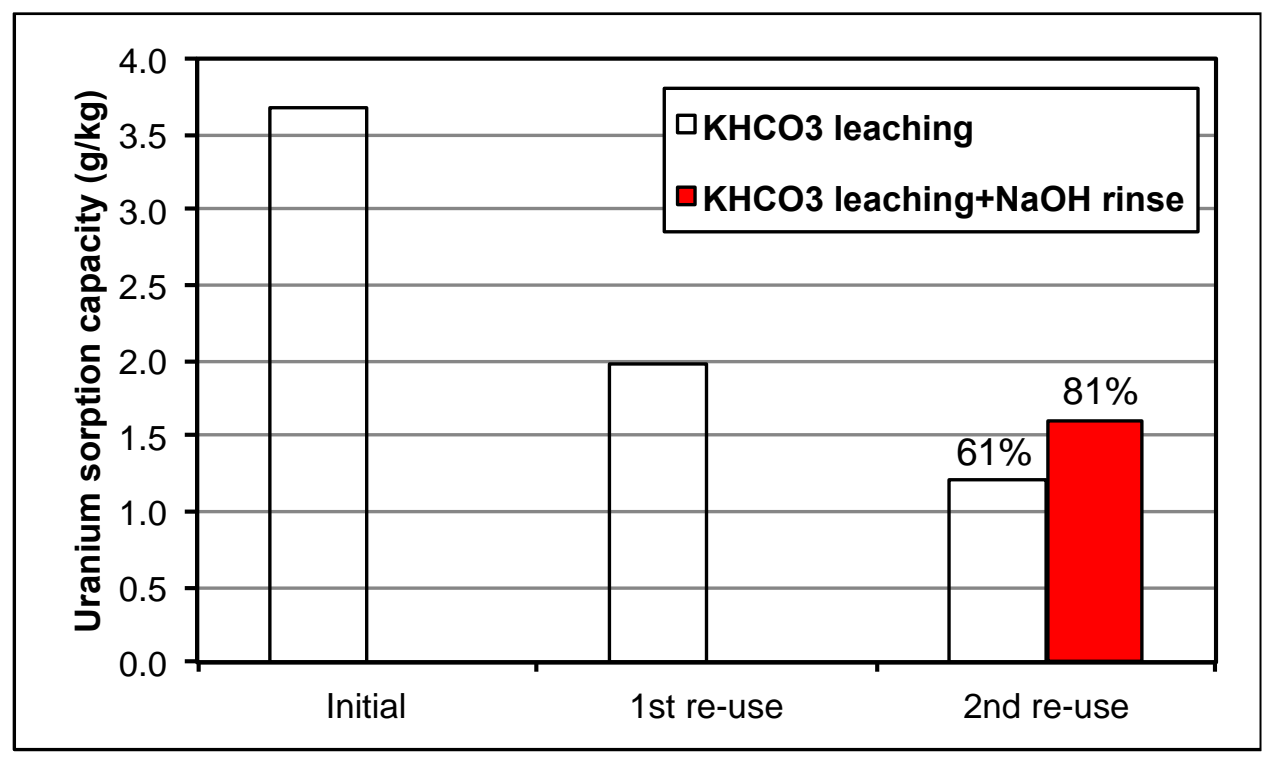

Figure 31. Comparison of $\mathrm{U}$ adsorption capacity for ORNL AF1 adsorbent fibers treated with $\mathrm{NaOH}$ after the first reuse (red bar) with results obtained from the $3 \mathrm{M} \mathrm{KHCO}_{3}$ elution/recycling experiment (blue columns). The percentage numbers above the columns are percentage recovery of $U$ adsorption capacity relative to the adsorption capacity of the first reused adsorbent.

\subsection{Conclusion}

All three of the tested recycling approaches with the ORNL AF1L2R3 amidoxime-based polymeric adsorbent produced $\mathrm{U}$ adsorption capacities upon reuse that were below expectation. The $\mathrm{KHCO}_{3}$ elution process was shown to be very selective for removing $U$ from amidoxime-based adsorbents, a very significant feature that can be capitalized on for the overall $\mathrm{U}$ recovery process. If an understanding of the mechanisms responsible for the loss of adsorption capacity upon elution can be identified, it is highly likely that an elution process can be developed that significantly improves adsorption capacity upon reuse. One area in particular that needs further exploration is the role that DOM adsorption from natural seawater plays in controlling adsorption capacity upon reuse. The $\mathrm{KHCO}_{3}$ elution process still holds a great deal of promise as a suitable and environmentally friendly method.

Japanese scientists have reported that there is about a $5 \%$ to $6 \%$ reduction in adsorption capacity following repeated acid elution and $\mathrm{KOH}$ reconditioning during adsorbent reuse in seawater (Seko et al., 2004). Hence, it is very surprising and disappointing that we observed a much more significant loss in adsorption capacity with the ORNL AF1 adsorbent following acid elution and $\mathrm{KOH}$ reconditioning for adsorbent reuse. The difference in response between the Japanese and ORNL amidoxime-based adsorbents likely is due to several factors, particularly synthesis and elution conditions.

The array of analysis methods used to probe the adsorbents' physical and chemical characteristics in relation to the elution schemes reveal a complex set of variables may be involved in assessing adsorbent performance and associated elution schemes in real seawater for extended periods. To Illustrate this point, there is a drastic drop in $\mathrm{U}$ adsorption capacity after recycling when comparing results of acid elution recycling from an artificial seawater system (20\% drop in capacity with batch artificial seawater) to a real seawater exposure (90\% drop in capacity) (Table 10 and Pan et al., 2014). No significant change in the uranium adsorption capacity was observed for up to six reuse cycles in artificial seawater 
experiments with $\mathrm{KHCO}_{3}$ leaching (data not shown), but a $40 \%$ drop was found in one reuse cycle in the real seawater adsorption system (Table 10). The difference in experimental results between artificial and real seawater may be due to a lack of competing ions in the artificial seawater, use of spiked high uranium concentrations in artificial seawater, the fact that artificial seawater is abiotic in nature and natural seawater is not, and the reduced time scale for studies in artificial seawater ( 1 to 2 days) compared to real seawater (6 to 8 weeks).

\subsection{References}

Benner R. In Biogeochemistry of Marine Dissolved Organic Matter; DA Hansell and CA Carlson, eds.; Academic Press: New York, 2002.

Clark DL, DE Hobart, and MP Neu. 1995. "Actinide Carbonate Complexes and Their Importance in Actinide Environmental Chemistry." Chem. Rev. 95:25-48.

Das S, AK Pandey, A Athawale, V Kumar, YK Bhardwaj, S Sabharwal, and VK Manchanda 2008. Chemical aspects of uranium recovery from seawater by amidoximated electron-beam-grafted polypropylene membranes. Desalination 232: 243-253

DOE. 2010. Nuclear Energy Research and Development Roadmap: Report to Congress. U.S. Department of Energy, Washington, D.C. Available at: http://energy.gov/ne/downloads/nuclear-energyresearch-and-development-roadmap.

Egawa H, T Nonaka, and M Nakayama. 1990. "Recovery of Uranium from Seawater. 7. Concentration and Separation of Uranium in Acidic Eluate." Ind. Eng. Chem. Res. 29: 2273.

Egawa H, N Kabay, T Shuto, and A Jyo. 1993. "Recovery of Uranium from Seawater. 13. Long-Term Stability Tests for High-Performance Chelating Resins Containing Amidoxime Groups and Evaluation of Elution Process." Ind. Eng. Chem. Res. 32:540-547.

Endrizzi F and L Rao. 2014. "Chemical Speciation of Uranium(VI) in Marine Environments: Complexation of Calcium and Magnesium Ions with $\left[\left(\mathrm{UO}_{2}\right)\left(\mathrm{CO}_{3}\right)_{3}\right]^{4}$ and the Effect on the Extraction of Uranium from Seawater.” Chem. Eur. J. 20:14499-14506.

Endrizzi F, A Melchior, M Tolazzi, and L Rao. 2015. "Complexation of uranium(VI) with glutarimidoxioxime: thermodynamic and computational studies." Dalton Trans., Article Online, April 30, 2015.

Hansell DA. 2013. "Recalcitrant dissolved organic carbon fractions." Annu. Rev. Mar. Sci. 5:421-445.

Hirotsu N, N Takagi, S Katoh, N Takai, M Seno, and T Itagaki. 1987. "Selective elution of uranium from amidoxime polymer II." Sep. Sci. Technol. 22:2217-2227.

Janke C, JS Dai, and Y Oyola. 2013. U.S. Patent 2012-13553288, 20130071659.

Kang SO, S Vukovic, R Custelcean, and BP Hay. 2012. "Cyclic Imide Dioximes: Formation and Hydrolytic Stability.” Ind Eng Chem Res. 51:6619-6624. 
Kim J, Y Oyola, C Tsouris, CR Hexel, RT Mayes, CJ Janke, and S Dai. "Characterization of Uranium Uptake Kinetics from Seawater in Batch and Flow-Through Experiments." 2013. Ind. Eng. Chem. Res. 52:9433-9440.

Kim J, C Tsouris, Y Oyola, CJ Janke, RT Mayes, S Dai, G Gill, L-J Kuo, J Wood, K-Y Choe, E Schneider, and H Lindner. 2014. "Uptake of Uranium from Seawater by Amidoxime-Based Polymeric Sorbent: Field Experiments, Modeling, and Updated Economic Assessment." Ind. Eng. Chem. Res. 53:6076-6083

Leggett CJ and R Linfeng. 2015a. "Complexation of calcium and magnesium with glutarimidedioxime: Implications for the extraction of uranium from seawater." Polyhedron 95:54-59.

Leggett CJ and R Linfeng. 2015b. "Complexation of Glutarimidedioxime with V(V), a Major Competing Ion for the Extraction of U(VI) from Seawater." Presentation at the ACS National Meeting, Denver, CO, March 21, 2015.

Ogawa H and E Tanoue. 2003. "Dissolved organic matter in oceanic waters." J. Oceanogr. 59:129-147.

Omichi H, A Katakai, T Sugo, and J Okamoto. 1986. "A new type of amidoxime-group-containing adsorbent for the recovery of uranium from seawater. III. Recycle use of adsorbent." Sep. Sci. Technol. 21:563-574.

Pan HB, L-J Kuo, J Wood, J Strivens, GA Gill, CJ Janke, and CM Wai. 2015. "Toward understanding $\mathrm{KOH}$ conditioning of amidoxime-based polymer adsorbents for sequestering uranium from seawater." Submitted to RSC Advances.

Pan HB, WS Liao, CM Wai, Y Oyola, CJ Janke, GX Tian, and LF Rao. 2014. "Carbonate- $\mathrm{H}_{2} \mathrm{O}_{2}$ leaching for sequestering uranium from seawater.” Dalton Trans. 43:10713-10718.

Schneider E and D Sachde. 2013 The Cost of Recovering Uranium from Seawater by a Braided Polymer Adsorbent System, Science \& Global Security: The Technical Basis for Arms Control, Disarmament, and Nonproliferation Initiatives, 21:2, 134-163, DOI: 10.1080/08929882.2013.798993

Seko N, A Katakai, M Tamada, T Sugo, and F Yoshii. 2004. "Fine Fibrous Amidoxime Adsorbent Synthesized by Grafting and Uranium Adsorption-Elution Cyclic Test with Seawater." Sep. Sci. Technol. 39(16): 3753-3767.

Shimizu T and M Tamada. 2004. "Practical scale system for uranium recovery from seawater using braid type adsorbent." Proceedings of Civil Engineering in the Ocean 20:617-622.

Sun X, C Xu, G Tian, and L Rao. 2013. "Complexation of glutarimidedioxime with Fe(III), Cu(II), $\mathrm{Pb}(\mathrm{II})$, and $\mathrm{Ni}(\mathrm{II})$, the competing ions for the sequestration of $\mathrm{U}(\mathrm{VI})$ from seawater." Dalton Trans. 42:14621-14627.

Suzuki T, K Saito, T Sugo, H Ogura and K Oguma. 2000. "Functional elution and determination of uranium and vanadium adsorbed on amidoxime fiber from seawater." Analytical Sciences 16:429-432.

Tamada M, N Seko, and F Yoshii. 2004. "Application of radiation-graft material for metal adsorbent and crosslinked natural polymer for healthcare product." Radiation Physics and Chemistry 71:221-225 
Tanaka K, K Kuma, K Hamasaki, and Y Yamashita. 2014. "Accumulation of humic-like fluorescent dissolved organic matter in the Japan Sea." Scientific Reports 4:5292.

Tian G, SJ Teat, Z Zhang, and L. Rao. 2012. "Sequestering uranium from seawater: binding strength and modes of uranyl complexes with glutarimidedioxime." Dalton Trans. 41:11579-11586. 